\title{
Exploring the kinetic selectivity of drugs targeting the $\beta_{1^{-}}$ adrenoceptor
}

David A. Sykes ${ }^{1,2, *}$, Mireia Jiménez-Rosés ${ }^{1,2}$, John Reilly ${ }^{3}$, Robin A. Fairhurst ${ }^{3}$, Steven J. Charlton ${ }^{1,2, *}$ and Dmitry B. Veprintsev ${ }^{1,2, *}$.

${ }^{1}$ Centre of Membrane Proteins and Receptors (COMPARE), University of Nottingham, Midlands, UK

${ }^{2}$ Division of Physiology, Pharmacology \& Neuroscience, School of Life Sciences, University of Nottingham, Nottingham, NG7 2UH, UK

${ }^{3}$ Novartis Institutes for BioMedical Research, CH-4002 Basel, Switzerland 


\section{Running title:}

The kinetic determinants of $\beta_{1}$-adrenoceptor binding affinity

\section{Corresponding author(s):}

Dr David A. Sykes

School of Life Sciences,

Queen's Medical Centre,

University of Nottingham,

Nottingham NG7 2UH

Prof Steven Charlton

School of Life Sciences,

Queen's Medical Centre,

University of Nottingham,

Nottingham NG7 2UH

Prof Dmitry B. Veprintsev

School of Life Sciences,

Queen's Medical Centre,

University of Nottingham,

Nottingham NG7 2UH

Number of text pages: 46

Number of tables: 1 
Number of figures: 7

Number of references: $60+$

Number of words in Abstract: 229

Number of words in Introduction: 920

Number of words in Discussion: 1593

\section{Abbreviations:}

$\mathrm{CHO}$, Chinese hamster ovary; HBSS, Hanks' balanced salt solution; [ $\left.{ }^{3} \mathrm{H}\right]-\mathrm{DHA}, 1-[4,6-$ propyl-3H] dihydroalprenolol; NSB, non-specific binding. 


\section{Abstract}

In this study, we report the $\beta_{1}$-adrenoceptor binding kinetics of several clinically relevant $\beta_{1 / 2}$-adrenoceptor $\left(\beta_{1 / 2} A R\right)$ agonists and antagonists. We demonstrate that the physicochemical properties of a molecule directly affect its kinetic association rate $\left(k_{\mathrm{on}}\right)$ and affinity for the target. In contrast to our findings at the $\beta_{2}$-adrenoceptor, a drug's immobilized artificial membrane partition coefficient $\left(\mathrm{K}_{\mathrm{IAM}}\right)$, reflecting both hydrophobic and electrostatic interactions of the drug with the charged surface of biological membranes, was no better predictor than simple hydrophobicity measurements such as $\log \mathrm{P}$ or $\log \mathrm{D}_{7.4}$, characterized by a distribution between water and a non-aqueous organic phase (e.g. n-octanol) at predicting association rate. Overall, this suggests that hydrophobic interactions rather than a combination of polar and hydrophobic interactions play a more prominent role in dictating the binding of these ligands to the $\beta_{1}$-adrenoceptor.

Using a combination of kinetic data, detailed structural and physicochemical information we rationalize the above findings and speculate that the association of positively charged ligands at the $\beta_{1} A R$ is curtailed somewhat by its predominantly neutral/positive charged extracellular surface. Consequently, hydrophobic interactions in the ligand binding pocket dominate the kinetics of ligand binding. In comparison at the $\beta_{2} A R$, a combination of hydrophobicity and negative charge attracts basic, positively charged ligands to the receptor's surface promoting the kinetics of ligand binding. Additionally, we reveal the potential role kinetics plays in the on-target and off-target pharmacology of clinically used $\beta$-blockers. 


\section{Introduction}

The $\beta_{1}$-adrenergic receptor is involved in the sympathetic nervous systems control of the circulation mainly via its stimulatory signaling effects on the heart. So called $\beta$ blockers, also known as $\beta$-adrenergic receptor blockers, decrease heart rate and blood pressure through their actions at $\beta_{1}$-adrenoceptors and are therefore useful in the treatment of hypertension and heart failure. The promiscuous binding of $\beta$-adrenergic ligands to the closely related subtypes of the $\beta$-adrenoceptor (e.g., the $\beta_{2}$-adrenergic receptor) leads to commonly observed side effects such as fatigue, decreased peripheral circulation and increased airway resistance. This cross reactivity has long been considered a risk factor in asthmatic patients, with deaths attributed to $\beta$-blockers use in the very early years of their use, leading to the recommendation that nonselective $\beta$-blockers be avoided in asthmatic subjects (Harries, 1981; Harrington, 2020). The heart is not the only target for the therapeutic action of $\beta$-blockers, reflected in their use in the treatment of migraine, essential tremor, pheochromocytoma, thyrotoxicosis anxiety and the most common form of glaucoma (Baker et al., 2011; Harrington, 2020). More recently reports suggest a role for $\beta$-blockers in the treatment of certain cancers (Gillis et al., 2021; Peixoto et al., 2020). In this regard it must be noted that not all clinically used $\beta$-blockers are indicated in all these conditions. For example, only the more lipophilic non-selective molecules which cross the blood brain barrier are used in the treatment of migraine.

Thus far pharmacologists have been limited to understanding $\beta$-adrenergic receptor selectivity largely in terms of binding receptor affinity in recombinant systems and in silico structural docking studies that reveal the most favorable, lowest energy binding pose of a ligand (Baker, 2005, 2010; Masureel et al., 2018; Warne et al., 2019; Warne et al., 2011; Warne et al., 2008). However, due to their high sequence and structural similarity the molecular basis of ligand selectivity between these two receptor subtypes remains to be fully understood. This has led to the suggestion that the kinetic process of ligand binding itself may contribute to ligand specificity for individual receptor subtypes. And although the process of ligand binding is not possible to study using direct 
structural methods, molecular dynamics (MD) studies have shed some light on the molecular basis of receptor selectivity and even on the pathway of ligand binding and dissociation (Dror et al., 2011; Gonzalez et al., 2011; Selvam et al., 2012).

Our previous studies of $\beta_{2}$-adrenergic receptor kinetics highlighted the importance of 'membrane like' polar and hydrophobic interactions in driving ligand binding through changes in ligand association rate (or $k_{\text {on }}$ ) (Sykes and Charlton, 2012; Sykes et al., 2014). By itself increased drug affinity for the membrane is unlikely to dictate receptor specific subtype specificity, unless of course a direct lipid entry pathway is involved as has been previously suggested before for the $\beta_{2}$-adrenoceptor (Mason et al., 1991). However MD simulation studies appear to rule out a direct lipid pathway over an aqueous route (Dror et al., 2011). Nonetheless, this still does not answer why certain hydrophobic ligands such as salmeterol show preferential binding to the $\beta_{2^{-}}$ adrenoceptor subtype. This appears based on mutation studies to be due partly to the presence of specific residues found on the surface of the $\beta_{2}$-adrenoceptor which are not found in the corresponding $\beta_{1}$-adrenoceptor (Baker et al., 2015; Isogaya et al., 1998).

Kinetic selectivity has been shown to be an important factor in dictating the therapeutic action of muscarinic $\mathrm{M}_{3}$ antagonists which target the lung to treat chronic obstructive pulmonary disease or COPD (Sykes et al., 2012; Tautermann et al., 2013). Here a longer residency time at the muscarinic $M_{3}$ receptor over the $M_{2}$ receptor subtype is favored from a therapeutic perspective helping to relax smooth muscle cells and open the airways. Blockade of $\mathrm{M}_{2}$ receptors results in increased acetylcholine release from vagal nerve endings which enhances bronchoconstriction and precipitates cardiac adverse effects, in particular increases in heart rate, and the induction of polymorphic ventricular tachycardia with the potential for sudden death (Costello et al., 1998; LaCroix et al., 2008; Oberhauser et al., 2001). In direct contrast the relevance of kinetic selectivity in the therapeutic action of $\beta$-blockers remains unexplored, largely due to a lack of information on the binding kinetics of these ligands at the $\beta_{1}$-adrenoceptor.

Historically the kinetics of $\beta_{1}$-adrenoceptors antagonists have been studied directly in native tissues using tritiated compounds. One of the very earliest examples was 
formulated in canine myocardium at physiological temperature using tritiated alprenolol, however such experiments are potentially complicated by the presence of multiple receptor subtypes (Alexander et al., 1975). More recently the kinetics of synthetic and endogenous agonists and antagonists have been studied albeit at room temperature (Boursier et al., 2020; Ramos et al., 2018; Xu et al., 2020).

The aim of this work was to determine the kinetics of a series of well-described $\beta_{1^{-}}$ adrenoceptor antagonists and agonists and several clinically relevant $\beta_{1}$-adrenoceptor antagonists under physiological conditions. One way to achieve this is to indirectly measure the kinetics of drug-receptor interaction using the competition association method first popularized by Motulsky and Mahan (1984) and one we have previously applied with some success to the study of $\beta_{2}$-adrenergic pharmacology (Sykes and Charlton, 2012; Sykes et al., 2014). A secondary aim was to determine if kinetic selectivity has any role to play in the known side effect profile of these widely prescribed compounds. A more detailed understanding of the molecular basis of $\beta_{1 / 2}$-adrenergic receptor antagonist selectivity is likely to provide a novel rationale for the discovery of more selective ligands which target the heart with potentially fewer side effects. 


\section{Materials and Methods}

$\left[{ }^{3} \mathrm{H}\right]-\mathrm{DHA} \quad$ (1-[4,6-propyl- $\left.{ }^{3} \mathrm{H}\right]$ dihydroalprenolol, specific activity $\left.91 \mathrm{Ci} \cdot \mathrm{mmol}^{-1}\right)$ was obtained from PerkinElmer Life and Analytical Sciences (Beaconsfield, UK). Ninety-sixdeep well plates and $500 \mathrm{~cm}^{2}$ cell culture plates were purchased from Fisher Scientific (Loughborough, UK). Millipore 96-well GF/B filter plates were purchased from Receptor Technologies (Warwick, UK). Sodium bicarbonate, ascorbic acid, EDTA, sodium chloride, GTP, bisoprolol hemifumarate, (S)-(-) atenolol, labetalol hydrochloride, $( \pm)$ metoprolol, carvedilol, (S)-(-) propranolol hydrochloride, salmeterol xinofoate, ICl118,551 hydrochloride, ( \pm ) sotalol hydrochloride, nadolol, (S)-(-) cyanopindolol hemifumarate, formoterol fumarate and CGP-20712A methanesulfonate were obtained from Sigma Chemical Co Ltd. (Poole, UK). Bucindolol, (S)-timolol maleate and CGP12177 hydrochloride were obtained from Tocris Cookson, Inc. (Bristol, UK). All cell culture reagents including Hanks' balanced salt solution (HBSS) and HEPES were purchased from Gibco (Invitrogen, Paisley, UK).

Cell culture and membrane preparation

$\mathrm{CHO}$ cells stably transfected with the human $\beta_{1}$-adrenoceptor were grown adherently in Ham's F-12 Nutrient Mix GlutaMAX-1, containing $10 \%$ fetal calf serum, and $0.5 \mathrm{mg} \cdot \mathrm{mL}^{-1}$ Geneticin (G-418). Cells were maintained at $37^{\circ} \mathrm{C}$ in $5 \% \quad \mathrm{CO}_{2} /$ humidified air and routinely subcultured at a ratio between 1:10 and 1:20 twice weekly using trypsin-EDTA to lift cells. Cell membranes were prepared and stored as described previously (Sykes \& Charlton 2012).

Common procedures applicable to all radioligand binding experiments

All radioligand binding experiments using 1-[4,6-propyl- $\left.{ }^{3} \mathrm{H}\right]$ dihydroalprenolol $\left(\left[{ }^{3} \mathrm{H}\right]-\mathrm{DHA}\right.$ specific activity $91 \mathrm{Ci} \cdot \mathrm{mmol}-1)$ were conducted in 96-deep well plates, in assay binding buffer, HBSS pH 7.4, 0.01\% ascorbic acid and $100 \mu \mathrm{M}$ GTP. GTP was included to remove the $\mathrm{G}$ protein-coupled population of receptors which can result in two binding sites in membrane preparations, because the Motulsky \& Mahan model is only appropriate for ligands competing at a single site. In all cases, nonspecific binding 
(NSB) was determined in the presence of $1 \mu \mathrm{M}$ propranolol. After the indicated incubation period, bound and free radiolabels were separated by rapid vacuum filtration using a FilterMate ${ }^{\mathrm{TM}}$ Cell Harvester (PerkinElmer Life and Analytical Sciences, Beaconsfield, UK) onto 96 well GF/B filter plates (Millipore, Watford UK) previously coated with $0.5 \%(\mathrm{w} / \mathrm{v})$ polyethylenimine and rapidly washed three times with ice-cold 75 mM HEPES, pH 7.4. After drying (>4 h), $40 \mathrm{~mL}^{\text {of Microscint }}{ }^{\mathrm{TM}} 20$ (PerkinElmer Life and Analytical Sciences) was added to each well and radioactivity was quantified using single photon counting on a TopCount ${ }^{\mathrm{TM}}$ microplate scintillation counter (PerkinElmer Life and Analytical Sciences). Aliquots of radiolabel were also quantified accurately to determine how much radioactivity was added to each well using liquid scintillation spectrometry on LS 6500 scintillation counter (Beckman Coulter, High Wycombe, UK). In all experiments, total binding never exceeded more than $10 \%$ of that added, limiting complications associated with depletion of the free radioligand concentration (Carter et al., 2007).

\section{Saturation binding studies}

$\mathrm{CHO}$ cell membranes containing the $\beta_{1}$-adrenoceptor were incubated in 96-deep well plates at $37^{\circ} \mathrm{C}$ in assay binding buffer with a range of concentrations of $\left[{ }^{3} \mathrm{H}\right]-\mathrm{DHA}(\sim 12-$ $0.01 \mathrm{nM}$ ) at $30 \mu \mathrm{g}$ per well, for $180 \mathrm{~min}$ with gentle agitation to ensure equilibrium was reached. Saturation binding was performed in a final assay volume of to $1.5 \mathrm{~mL}$ to avoid significant ligand depletion.

Determination of the association rate $\left(k_{o n}\right)$ and dissociation rate $\left(k_{\text {off }}\right)$ of $\left[{ }^{3} H\right]-D H A$

To accurately determine $k_{\text {on }}$ and $k_{\text {off }}$ values, the observed rate of association $\left(k_{o b}\right)$ was calculated using at least three different concentrations of $\left[{ }^{3} \mathrm{H}\right]-\mathrm{DHA}$. The appropriate concentration of radioligand was incubated with $\beta_{1}$-adrenoceptor $\mathrm{CHO}$ cell membranes (30 $\mu \mathrm{g} \cdot$ per well) in assay binding buffer with gentle agitation (final assay volume 500 $\mu \mathrm{L})$. Exact concentrations were calculated in each experiment by liquid scintillation counting. Free radioligand was separated by rapid filtration at multiple time points to construct association kinetic curves as described previously by Sykes \& Charlton 
(2012). The resulting data were globally fitted to the association kinetic model (Equation 2) to derive a single best fit estimate for $k_{\text {on }}$ and $k_{\text {off }}$ as described under Data analysis.

Determination of affinity constants $\left(K_{\mathrm{i}}\right)$

To obtain affinity estimates of unlabelled ligand, $\left[{ }^{3} \mathrm{H}\right]$-DHA competition experiments were performed at equilibrium. $\left[{ }^{3} \mathrm{H}\right]-\mathrm{DHA}$ was used at a concentration of approximately $3 \mathrm{nM}$ (final assay volume of $0.5 \mathrm{~mL}$ ), such that the total binding never exceeded more than $10 \%$ of that added. Radioligand was incubated in the presence of the indicated concentration of unlabelled ligand and $\mathrm{CHO}$ cell membranes (30 $\mu \mathrm{g}$ per well) at $37^{\circ} \mathrm{C}$, with gentle agitation for $180 \mathrm{~min}$.

\section{Competition binding kinetics}

The kinetic parameters of unlabelled ligand were assessed using a competition kinetic binding assay originally described by Motulsky \& Mahan (1984) and developed for the $\beta_{1}$-adrenoceptor by Sykes \& Charlton (2012). This approach involves the simultaneous addition of both radioligand and competitor to receptor preparation, so that at $\mathrm{t}=0$ all receptors are unoccupied.

Approximately $3 \mathrm{nM}\left[{ }^{3} \mathrm{H}\right]-\mathrm{DHA}$ (a concentration which avoids ligand depletion in this assay volume) was added simultaneously with the unlabelled compound $(a t=0)$ to $\mathrm{CHO}$ cell membranes containing the human $\beta_{1}$-adrenoceptor (30 $\mu \mathrm{g}$. per well) in $500 \mu \mathrm{L}$ assay buffer. The degree of $\left[{ }^{3} \mathrm{H}\right]-\mathrm{DHA}$ bound to the receptor was assessed at several time points by filtration harvesting and liquid scintillation counting, as described previously. NSB was determined as the amount of radioactivity bound to the filters and membrane in the presence of propranolol $(1 \mu \mathrm{M})$ and was subtracted from each time point, meaning that $\mathrm{t}=0$ was always equal to zero. Each time point was conducted on the same 96 -deep well plate incubated at $37^{\circ} \mathrm{C}$ with constant agitation. Reactions were considered stopped once the membranes reached the filter, and the first wash was applied within $1 \mathrm{~s}$. A single concentration of unlabeled competitor was tested, as rate parameters were shown to be independent of unlabeled ligand concentration (data not 
shown). All compounds were tested at either 1-, 3-, 10- or 100 -fold their respective $K_{\mathrm{i}}$ and data were globally fitted using Equation 3 to simultaneously calculate $k_{\text {on }}$ and $k_{\text {off }}$. Different ligand concentrations were chosen as compounds with a long residence time equilibrate more slowly so a higher relative concentration is required to ensure the experiments reach equilibrium within a reasonable time frame (90 $\mathrm{min})$, whilst still maintaining a good signal to noise. The actual concentrations used were selected from a preliminary experiment using three different concentrations of each ligand (data not shown).

$\log D_{7.4}$ and Immobilised Artificial Membrane (IAM) Chromatography

All HPLC experiments were carried out as previously described by Sykes et al., (2014).

\section{Data analysis and statistical procedures}

As the amount of radioactivity varied slightly for each experiment $(<5 \%)$, data are shown graphically as the mean \pm range for individual representative experiments, whereas all values reported in the text and tables are mean \pm SEM for the indicated number of experiments unless otherwise stated. All experiments were analyzed by either Deming regression or non-linear regression using Prism 8.0 (GraphPad Software, San Diego, CA, USA).

Competition binding.

Competition displacement binding data were fitted to sigmoidal (variable slope) curves using a four-parameter logistic equation:

$Y=$ Bottom $+($ Top - Bottom $)\left(1+10\left(\log \mathrm{EC}_{50}-X\right) \cdot\right.$ HillSlope $)$

$I_{50}$ values obtained from the inhibition curves were converted to $K_{\mathrm{i}}$ values using the method of Cheng and Prusoff (1973).

Association binding. 
$\left[{ }^{3} \mathrm{H}\right]-\mathrm{DHA}$ association data were globally fitted to Equation 2, where $\mathrm{L}$ is the concentration of radioligand in nM using GraphPad Prism 8.0 to determine a best fit estimate for $k_{\text {on }}$ and $k_{\text {off. }}$

$k_{\mathrm{ob}}=[\mathrm{L}] \cdot k_{\mathrm{on}}+k_{\mathrm{off}}$

Competition kinetic binding

Association and dissociation rates for unlabelled agonists were calculated using the equations described by Motulsky and Mahan (1984) using a global fitting model:

$K_{A}=k_{1}[L]+k_{2}$

$K_{B}=k_{3}[I]+k_{4}$

$S=\sqrt{\left(\left(K_{A}-K_{A}\right)^{2}+4 \cdot k_{1} \cdot k_{3} \cdot L \cdot I \cdot 10^{-18}\right)}$

$K_{F}=0.5 *\left(K_{A}+K_{B}+S\right)$

$K_{S}=0.5 *\left(K_{A}+K_{B}-S\right)$

$Q=\frac{B_{\max } * K_{1} * L * 10^{-9}}{K_{F}-K_{S}}$

$\mathrm{Y}=Q \cdot\left(\frac{k_{4} \cdot\left(K_{F}-K_{S}\right)}{K_{F} \cdot K_{S}}+\frac{k_{4}-K_{F}}{K_{F}} \exp ^{\left(-K_{F} \cdot X\right)}-\frac{k_{4} K_{S}}{K_{S}} \exp ^{\left(-K_{S} \cdot X\right)}\right)$

where $X$ is time (min), $Y$ is specific binding (c.p.m.), $k 1$ is $k_{\text {on }}$ of the tracer $\left[{ }^{3} \mathrm{H}\right]-\mathrm{DHA}, k 2$ is $k_{\text {off }}$ of the tracer $\left[{ }^{3} \mathrm{H}\right]-\mathrm{DHA}, L$ is the concentration of $\left[{ }^{3} \mathrm{H}\right]-\mathrm{DHA}$ used $(\mathrm{nM})$ and $l$ is the concentration of unlabeled agonist $(n M)$. Fixing the above parameters allowed the following to be simultaneously calculated: Bmax is total binding (c.p.m.), $k 3$ is association rate of unlabeled ligand $\left(\mathrm{M}^{-1} \mathrm{~min}^{-1}\right)$ or $k_{\mathrm{on}}$, and $k 4$ is the dissociation rate of unlabelled ligand $\left(\mathrm{min}^{-1}\right)$ or $k_{\text {off }}$.

Linear correlations 
The correlation between datasets was determined by calculating a Pearson correlation coefficient (presented as $r^{2}$ the coefficient of determination, which shows percentage variation in $y$ which is explained by all the $x$ variables together) in GraphPad Prism 8.0.

\section{PDBs structures and hydrophobic and electrostatic surface maps}

The crystal structures of the $\beta_{1} A R$ (Xu et al., 2020) and $\beta_{2} A R$ (Staus et al., 2016) were obtained from the Protein Data Bank (PDB entries $7 B V Q$ and $5 \mathrm{JQH}$, respectively). The hydrophobic surface map was obtained using a modified version (changing the scale of colours to purple and yellow) of color_h.py script (pymolwiki.org/index.php/Color_h) using PyMOL. For production of the electrostatic surface map, we used the PyMOL APBS electrostatic plugin using the default parameters (changing the scale colours to blue and red only) (MG Lerner and HA Carlos. APBS plugin for PyMOL, 2006, University of Michigan, Ann Arbor). 


\section{Results}

\section{Equilibrium and kinetic binding parameters for $\beta_{1}$-adrenoceptor ligands}

Initially the binding affinity of the radioligand $\left[{ }^{3} \mathrm{H}\right]$-DHA for the $\beta_{1}$-adrenoceptor (shown in Figure 1A) was measured at equilibrium in Hanks' Balanced Salt Solution containing GTP $(100 \mu \mathrm{M})$ at $37^{\circ} \mathrm{C}$. GTP was included to ensure that agonist binding only occurred to the uncoupled form of the receptor. Binding affinities ( $K_{i}$ values) for the $\beta_{1^{-}}$ adrenoceptor ligands determined in the presence to GTP are summarized in Table 1 and associated curves are presented in Figure 1B-D. To determine the association and dissociation rates of the $\beta_{1}$-adrenoceptor ligands, we utilized a competition kinetic radioligand binding assay as previously described by Sykes \& Charlton (2012). Firstly, we characterized the binding kinetics of the radiolabelled ligand $\left[{ }^{3} \mathrm{H}\right]$-DHA by monitoring the observed association rates at 3 different ligand concentrations (Figure 2A). The observed rate of association was related to $\left[{ }^{3} \mathrm{H}\right]-\mathrm{DHA}$ concentration in a linear fashion (Figure 2B). Kinetic rate parameters for $\left[{ }^{3} \mathrm{H}\right]$-DHA were calculated by globally fitting the association time courses, resulting in a $k_{\text {on }}$ of $5.28 \pm 0.48 \times 10^{9} \mathrm{M}^{-1} \mathrm{~min}^{-1}$ and a $k_{\text {off }}$ of $0.46 \pm 0.03 \mathrm{~min}^{-1}\left(K_{\mathrm{d}}=0.94 \pm 17 \mathrm{nM}\right)$.

Representative kinetic competition curves for selected $\beta$-adrenoceptor ligands are shown in Figure $3 \mathrm{~A}-\mathrm{H}$. Progression curves for $\left[{ }^{3} \mathrm{H}\right]-\mathrm{DHA}$ alone and in the presence of competitor were globally fitted to Equation 3 enabling the calculation of both $k_{\text {on }}(k 3)$ and $k_{\text {off }}(k 4)$ for each of the ligands, as reported in Table 1 . There was a very wide range in dissociation rates for the different ligands, with drug-target residency times ( $\left.1 / k_{\text {off }}\right)$ ranging between $0.07 \mathrm{~min}$ for the rapidly dissociating salmeterol to $66.67 \mathrm{~min}$ for cyanopindolol. To validate the rate constants, the kinetically derived $K_{d}$ values $\left(k_{\text {off }} / k_{\text {on }}\right)$ were compared with the affinity constant $\left(K_{\mathrm{i}}\right)$ obtained from equilibrium competition binding experiments (Supplemental Figure 1). There was a very good correlation $\left(r^{2}=\right.$ $0.97, P<0.0001)$ between these two values, indicating the kinetics parameters were accurate. 


\section{Measurements of lipophilicity and membrane interactions}

The degree of membrane interaction, denoted $K_{\mathrm{IAM}}$, assessed using a chromatographic method and calculated $\log \mathrm{P}$ (clogP) values and the measured partition coefficient $\log \mathrm{D}_{7.4}$ are detailed in (Sykes et al., 2014). Drug membrane interaction is assessed using a chromatographic method that utilises immobilized artificial membranes (IAMs) consisting of monolayers of phospholipid covalently immobilized on a silica surface, mimicking the lipid environment of a fluid cell membrane on a solid matrix (Liu et al., 2001; Sykes et al., 2014). Compounds with longer retention times on this column have higher affinity for phospholipids and will therefore theoretically have a higher calculated membrane partition coefficient, denoted $K_{\text {IAM }}$. The main difference between the $\log \mathrm{D}_{7.4}$ measure, that reflects hydrophobicity of the compound and IAM systems being the key role of electrostatics in the differential binding of the charged ligands to the anisotropic IAM column (Vrakas et al., 2008), mimicking the effects seen in biological membranes.

\section{Relationship between kinetics and membrane interactions}

The association rate parameter $k_{\text {on }}$ is calculated from the observed on-rate ( $\left.k_{\text {obs }}\right)$ which is highly dependent on drug concentration. We have demonstrated previously that drugs possessing a high membrane affinity appear to have a more rapid association rate, potentially due to an increase in the local concentration of compound (Sykes et al., 2014; Gherbi et al., 2017).

The degree of membrane interaction is routinely assessed using a chromatographic method. The calculated membrane partition coefficient, denoted $K_{\mathrm{IAM}}, \log \mathrm{P}$ (clogP) and the measured partition coefficient $\log \mathrm{D}_{7.4}$ used in the following plots are detailed in Sykes et al., 2014. Test compound Log $D_{7.4}$ values were significantly correlated $\left(r^{2}=\right.$ $0.32, P=0.019$ ) with $k_{\text {on }}$ determined in the competition kinetic assay (Figure $4 \mathrm{~A}$ ), with lipophilic compounds having a faster association rate. A very similar correlation of $k_{\text {on }}$ with $\log K_{\text {IAM }}$ was observed (Figure $4 \mathrm{~B}, r^{2}=0.35, P=0.013$ ), suggesting that a simple isotropic, single parameter model may be sufficient to describe the interaction of these drugs with the $\beta_{1}$-adrenoceptor. This was supported by comparisons between clogP 
and $k_{\mathrm{on}}$ which also showed a better correlation than observed with $\mathrm{K}_{\mathrm{IAM}}\left(r^{2}=0.48\right.$, $P<0.002$, data not shown). CGP20712A was excluded from these and subsequent analysis as no $K_{\mathrm{IAM}}$ data or corresponding $\beta_{2} \mathrm{AR}$ binding data was available.

The dissociation rate (or $k_{\text {off }}$ ) of a drug is not dependent upon drug concentration, so should be independent of the affinity of interaction with the membrane. Reassuringly, when the $k_{\text {off }}$ for each compound was compared to either its $\log D_{7.4}$ or $\log K_{\text {IAM }}$ no correlation was observed ( $P>0.05$, Figures $4 \mathrm{C}$ and $4 \mathrm{D}$ respectively).

The role of kinetics in dictating $\beta_{1}$-adrenoceptor compound affinity is presented in Figure $5 \mathrm{~A}$. Of the clinically used $\beta$-blockers under study, bisoprolol and nadolol stand out as possessing relatively slow on-rates in the region of $\sim 10^{7} \mathrm{M}^{-1} \mathrm{~min}^{-1}$ and relatively slow off rates $\left(\sim 0.1 \mathrm{~min}^{-1}\right)$. In contrast other clinically used agents such as metoprolol and atenolol have much faster dissociation rates $\left(3-10 \mathrm{~min}^{-1}\right)$ but higher relative association rates.

A comparison $\beta_{1 / 2}$-adrenoceptor compound dissociation and association kinetics is presented in Figure 5B to $\mathrm{C}$. Of the clinically used $\beta$-blockers bisoprolol again stands out as the only truly $\beta_{1}$-adrenoceptor selective compound based on its kinetic affinity, a feature that is seemingly dictated by its dissociation rate from the $\beta_{1}$-adrenoceptor (see Figure 5B and D). The majority of ligands demonstrate a faster association rate at the $\beta_{2}$-adrenoceptor apart from the clinically used $\beta$-blocker atenolol (Figure 5C). Other key observations in terms of understanding $\beta$-adrenergic ligand selectivity are the pronounced reduction in the $\beta_{1}$-adrenoceptor association and dissociation rate of salmeterol relative to salbutamol when we compare kinetic values across the two receptors (Figure 5B and C). Similarly, ICI 118, 551 lower affinity for the $\beta_{1^{-}}$ adrenoceptor appears to be dictated by a combination of a reduced association and increased dissociation rate.

Using kinetic parameters to model the rate of receptor occupancy and dissociation from the $\beta_{1}$ and $\beta_{2}$ adrenoceptors 
The rate of receptor occupancy is one factor which could potentially play a significant role in the rate of onset of the actions of clinically used $\beta$-blockers. To investigate this, we stimulated their $k_{\mathrm{obs}}$ at the $\beta_{1}$ and $\beta_{2}$ adrenoceptors using a concentration $30^{*} K_{\mathrm{d}}$ their $\beta_{1}$-adrenoceptor affinity. Under these conditions there were clear differences in the rate of association of the four clinically used compounds with bisoprolol and carvedilol exhibiting a slower rate of $\beta_{1 / 2}$ receptor occupancy than the other clinically used ligands tested metoprolol and atenolol (Figure 6A-D) that saturated the receptors faster.

Another factor which could play a role in the duration of action (DOA) of clinically used $\beta$-blockers is their rates of dissociation from the $\beta$-adrenoceptors. In the simulations compound dissociation is initiated by the removal of free ligand at the 5 min mark. These simulations show that for atenolol and metoprolol receptor binding is fully reversed within $5 \mathrm{~min}$, suggesting that dissociation rate has little or no role to play in the DOA of these two clinically used compounds (Figure 6B and D). Atenolol achieves a marginally lower level of occupancy at the $\beta_{2}$-adrenoceptors but its slower dissociation rate from this receptor equates to a marginally extended occupancy at this receptor.

In contrast dissociation of bisoprolol is noticeably slower from the $\beta_{1}$-adrenoceptors compared to the $\beta_{2}$-adrenoceptor. And whilst full dissociation occurs from the $\beta_{2^{-}}$ adrenoceptor in a matter of seconds, it takes approximately 40 min for full dissociation from the $\beta_{1}$-adrenoceptor (Figure $6 \mathrm{~A}$ ). Carvedilol is a $3^{\text {rd }}$ generation high affinity $\beta$ blocker and it is noticeable that it displays both higher affinity for the $\beta_{2}$-adrenoceptor but also a much slower rate of dissociation which leads to an extended occupancy at this receptor (Figure 6C). $\quad \beta_{1}$-adrenoceptors residence time values from these simulations are detailed in Table 1. Residence time values for $\beta_{2}$-adrenoceptors were taken from a previous publication (Sykes et al., 2014). 


\section{Discussion}

This study reports the kinetic rate constants of a number of $\beta_{1}$-adrenoceptor antagonists and agonists under physiological conditions allowing direct comparisons with earlier kinetic studies of the $\beta_{2}$-adrenoceptor (Sykes and Charlton, 2012; Sykes et al., 2014). Previous findings demonstrate how local drug concentrations near receptors embedded in biological membranes can directly influence their observed pharmacology (Gherbi et al., 2018; Sykes et al., 2014). Having established that a membrane bilayer acts as a medium by which drug molecules interact or locate low concentrations of a receptor, we proposed that compounds with high membrane partitioning would result in increased values of $k_{\text {on }}$. We have now extended these observations to include the $\beta_{1^{-}}$ adrenoceptor, comparing observed kinetic rate parameters with the degree of interaction with immobilized artificial membranes $\left(\mathrm{K}_{\mathrm{IAM}}\right)$ and measures of lipophilicity ( $\log P$ and $\log D_{7.4}$ ). As predicted the association rate of the compounds was seemingly directly influenced by their lipophilicity $\left(\log \mathrm{D}_{7.4}\right)$ however surprisingly the magnitude of interaction with the membrane surrounding the receptor, as determined through the artificial membrane partition coefficient (or $\mathrm{K}_{\mathrm{IAM}}$ ), did not further enhance this correlation.

In the previous study of the $\beta_{2}$-adrenoceptor, we hypothesized that the membrane itself could interact specifically with drugs (Sargent and Schwyzer, 1986), through ionic and hydrogen-bonding interactions (Avdeef et al., 1998), effectively concentrating drug molecules close to the surface of the membrane (relative to the bulk solution). In addition to the drug concentrating effect of the membrane, the loss of drug associated water (Dror et al., 2011), and lateral diffusion across a 2-dimensional cellular surface (rather than 3-dimensions in aqueous bulk) could all contribute to increased ligandreceptor association rates (McCloskey and Poo, 1986). These rate enhancing effects may not only be applied to membrane-like structures (e.g., phospholipids) but also the extracellular surfaces of the receptor itself (e.g., amino acids with a polar, hydrophilic and a nonpolar, hydrophobic end). A compound can have the right physicochemical properties to facilitate a fast on-rate but it must also have the right complementary structural features to facilitate its interaction with the receptors binding pocket. 
Mutational, crystal modelling and docking studies have highlighted the key role that specific regions of these receptors forming the entrance to the binding pocket, play in dictating overall drug-receptor affinity (Baker et al., 2015; Dror et al., 2011; Isogaya et al., 1999; Kaszuba et al., 2010; Kikkawa et al., 1998; Plazinska et al., 2013; Plazinska et al., 2015; Warne et al., 2008) and kinetics (Xu et al., 2020). A comparison of the residues of both $\beta$-adrenoceptor subtypes has suggested the importance of nonconserved electrostatic interactions as well as conserved aromatic contacts in the early steps of the binding process (Selvam et al., 2012; Xu et al., 2020). Similarly, on exit molecules have been shown to pause in what would now be termed the extracellular vestibule, a site 9-15 $\AA$ from the orthosteric binding site. These same sites have been shown to serve as secondary binding pockets during MD simulations of ligand entry (Dror et al., 2011; Gonzalez et al., 2011).

Based on the above one plausible explanation for differences in drug-receptor subtype association rate stems from the different amino acid composition of their vestibular regions (Masureel et al., 2018; Vanni et al., 2009; Warne et al., 2008). The extracellular vestibule of the $\beta_{2} A R$ is well known to have a more extensive polar network (Ring et al., 2013; Xu et al., 2020). In the $\beta_{2}$-adrenoceptor structure, the polar hydrophobic amino acid Tyr308 ${ }^{7.35 \times 34}$ contains an oxygen atom in the side chain which is capable of acting as a $\mathrm{H}$-bond donor or acceptor and has been postulated to form a key node in the pathway to successful ligand binding (Dror et al., 2011). Superscript notation corresponds to the GPCRDB numbering (Isberg et al., 2016). Mutation of this residue to structurally equivalent phenylalanine found in the $\beta_{1}$-adrenoceptor structure

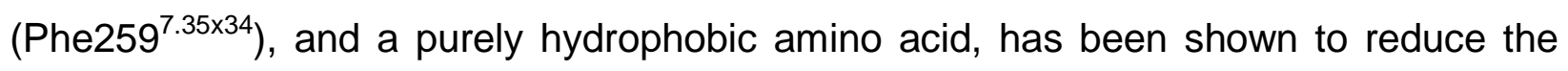
binding affinity of a wide range of $\beta_{2}$ adrenergic ligands firmly establishing its importance in the binding process (Baker et al., 2015). The absence of this key polar residue in the $\beta_{1}$-adrenoceptor structure means that for certain ligands the connection between their ability to interact with the membrane and subsequent probability of a successful binding event is reduced. The idea that specific residues (hydrophobic/charged) residues may guide lipophilic polar molecules into the orthosteric binding pocket, it is very much in line with predictions from MD studies which highlight the probability of binding from different 
regions of the outer pocket (Dror et al., 2011). This concept is also consistent with the idea that the receptor itself can influence local drug concentrations and in so doing directly dictate drug-receptor affinity through an increase in measured on-rate (Gherbi et al., 2018). The relative differences in extracellular surface lipophilicity and polarity between the $\beta_{1}$ and $\beta_{2}$-adrenoceptor subtypes are summarized in Figure 7.

Ligand binding likely occurs in a multistage process: Initially the membrane acts as a vehicle to concentrate drug molecules at the receptor surface contributing to the loss of water molecules and allowing binding to proceed in several 'smaller' steps, with lower energy barriers compared with a one-step mechanism, culminating in a more rapid binding process (AP and Guo, 2019; Vauquelin, 2016). Diffusion in 2D allows drugs molecules to rapidly reach their target receptor through a reduction in dimensionality. Drug then enters the vestibule, followed by interaction of a ligand with key residues in the outer vestibule, for example in the $\beta_{2}$-adrenoceptor structure certain basic drug molecules form a loose interaction with the more numerous polar amino acid residues eg. Tyr308 $8^{7.35 \times 34}(\mathrm{Y})$, thereby increasing the probability of a successful drug binding event. Finally, as a ligand enters the negatively charged binding pocket the positive charge of the ligands contributes to their rapid association with the orthosteric binding site.

It is reasonable to assume that the process of unbinding and binding follows a similar path but in opposite directions. A slower dissociation rate from the $\beta_{2^{-}}$adrenoceptor could be partly caused by an extended residence time in the vestibule of receptor, the result of both the polar and hydrophobic interactions important in facilitating ligand association. This being the case the absence of Tyr308 ${ }^{7.35 \times 34}$ in the $\beta_{1}$-adrenoceptor structure should result in an overall more rapid dissociation rate for key $\beta_{2}$-adrenoceptor specific ligands. This idea appears to be consistent with both the kinetic on and off-rates measured at these two receptor subtypes (Ramos et al., 2018; Sykes et al., 2012; Sykes et al., 2014) and the reduced affinities observed for ligands following the Y308F mutation (Baker et al., 2015). The relationship between association and dissociation 
rates for these ligands across these two receptor subtypes is shown in Supplementary Figure 2.

Kinetic selectivity is likely to be one of the key steps to reducing the side effect profile of $\beta$-adrenergic compounds. This tactic has proved to be effective in reducing the side effect profile of muscarinic $\mathrm{M}_{3}$ antagonists which based on affinity values cannot be considered particularly selective for one receptor subtype over another (Sykes et al., 2012; Tautermann et al., 2013). In the current study, we are able for the first time to rationalize the improved affinity of bisoprolol for the $\beta_{1}$-adrenoceptor over the $\beta_{2^{-}}$ adrenoceptor which results from its much-reduced dissociation rate (50-fold, see Figure 5b and 6a) (Sykes et al., 2014).

Bisoprolol's use in the clinic in patients with chronic heart failure and COPD is recognized as being associated with fewer side effects and potentially an improvement in mortality compared to the other $\beta$-blockers a fact which could be rationalized based on its improved kinetic selectivity for the $\beta_{1}$-adrenoreceptors, cumulating in fewer offtarget effects and characterized by its slow elimination and accumulation in the heart (Kang et al., 2021; Kubota et al., 2015; Lainscak et al., 2011; Liao et al., 2017; Su et al., 2016; Taniguchi et al., 2013). Other clinically used $\beta$-blockers which are considered cardio-selective include metoprolol and atenolol. However, based on the current data only atenolol can be considered marginally selective in terms of its overall affinity for $\beta_{1}$ and $\beta_{2}$-adrenoceptors. Neither drug can be considered kinetically selective in terms of their measured off-rates. Other non-selective $\beta_{2}$-adrenoceptor blockers such as carvedilol appear to be if anything more selective for $\beta_{2}$-adrenoreceptors over $\beta_{1^{-}}$ adrenoreceptors with repercussions for patients with underlying respiratory disease (Baker and Wilcox, 2017; Benson et al., 1978) where greater reductions in FEV (lung function) have been observed (Dungen et al., 2011; Jabbal et al., 2017; Jabbour et al., 2010) (see Figure 6).

Bisoprolol selective effects in the heart are clearly beneficial in the patients with heart and lung disease but in terms of the treatment of heart failure some reports suggest that carvedilol may produce equivalent or an improved overall reduced chance of all-cause 
mortality in systolic heart failure compared to other more selective agents such as bisoprolol (Bølling et al., 2014; Choi et al., 2019; DiNicolantonio et al., 2013; Hart, 2000; Hulkower et al., 2015; Rain and Rada, 2015; Remme, 2010; Wikstrand et al., 2014). Any number of factors could contribute to this including carvedilol's relatively slower dissociation from the $\beta_{1}$-adrenoreceptor or its vasodilatory alpha-receptor blocking effects (Metra et al., 2004; Remme, 2010; Weir and Dargie, 2005). Alternatively, its apparent kinetic selectivity for the $\beta_{2}$-adrenoreceptor, and/or biased signaling profile could potentially contribute to beneficial remodeling effects in the heart (Kim et al., 2014; Wisler et al., 2007).

In conclusion, we hope that the new kinetic data outlined in this study will reignite research into the discovery and development of kinetically selective ligands for the $\beta_{1}$ adrenoceptor, thereby reducing the overall burden of side effects associated with the use of $\beta$-blockers.

\section{Author Contributions}

Participated in research design: Sykes, Charlton, Veprintsev

Conducted experiments: Sykes, Reilly, Jiménez-Rosés

Performed data analysis: Sykes, Jiménez-Rosés, Reilly

Wrote or contributed to writing on manuscript: Sykes, Charlton, Jiménez-Rosés, Veprintsev, Reilly, Fairhurst 
bioRxiv preprint doi: https://doi.org/10.1101/2021.08.31.458064; this version posted September 1, 2021. The copyright holder for this preprint (which was not certified by peer review) is the author/funder, who has granted bioRxiv a license to display the preprint in perpetuity. It is made available under aCC-BY 4.0 International license.

\section{Financial Support}

This study was financed by Novartis Institutes for Biomedical Research. 


\begin{tabular}{|c|c|c|c|c|c|}
\hline Ligand & $k_{\text {off }}\left(\min ^{-1}\right)$ & $k_{\mathrm{on}}\left(\mathrm{M}^{-1} \mathrm{~min}^{-1}\right)$ & $\begin{array}{l}\text { Residence } \\
\text { time (min) }\end{array}$ & $\mathrm{p} K_{\mathrm{d}}$ & $\mathbf{p} K_{\mathrm{i}}$ \\
\hline Bisoprolol & $0.14 \pm 0.06$ & $1.96 \pm 0.26 \times 10^{7}$ & 7.14 & $8.20 \pm 0.13$ & $7.86 \pm 0.11$ \\
\hline Atenolol & $6.19 \pm 2.38$ & $4.03 \pm 1.29 \times 10^{7}$ & 0.16 & $6.84 \pm 0.04$ & $6.59 \pm 0.22$ \\
\hline Labetolol & $1.74 \pm 0.55$ & $2.85 \pm 0.91 \times 10^{8}$ & 0.57 & $8.21 \pm 0.07$ & $8.01 \pm 0.12$ \\
\hline Metoprolol & $3.41 \pm 0.85$ & $1.24 \pm 0.11 \times 10^{8}$ & 0.29 & $7.59 \pm 0.10$ & $7.20 \pm 0.15$ \\
\hline Bucindolol & $0.11 \pm 0.02$ & $1.11 \pm 0.25 \times 10^{9}$ & 9.09 & $10.00 \pm 0.04$ & $9.57 \pm 0.11$ \\
\hline Carvedilol & $0.09 \pm 0.02$ & $1.97 \pm 0.39 \times 10^{9}$ & 11.11 & $10.36 \pm 0.13$ & $9.84 \pm 0.23$ \\
\hline Propranolol & $0.91 \pm 0.03$ & $1.28 \pm 0.22 \times 10^{9}$ & 1.10 & $9.13 \pm 0.09$ & $9.51 \pm 0.09$ \\
\hline Salmeterol & $14.3 \pm 3.65$ & $2.63 \pm 0.21 \times 10^{7}$ & 0.07 & $6.29 \pm 0.08$ & $5.92 \pm 0.05$ \\
\hline ICI 118, 551 & $7.40 \pm 1.31$ & $6.80 \pm 2.40 \times 10^{7}$ & 0.14 & $6.88 \pm 0.16$ & $6.14 \pm 0.13$ \\
\hline Sotalol & $8.49 \pm 3.23$ & $8.47 \pm 3.16 \times 10^{6}$ & 0.12 & $6.00 \pm 0.03$ & $5.60 \pm 0.05$ \\
\hline Nadolol & $0.17 \pm 0.03$ & $7.68 \pm 0.79 \times 10^{6}$ & 5.88 & $7.65 \pm 0.04$ & $7.47 \pm 0.15$ \\
\hline Formoterol & $9.97 \pm 2.43$ & $1.68 \pm 0.11 \times 10^{7}$ & 0.10 & $6.25 \pm 0.12$ & $5.84 \pm 0.05$ \\
\hline Timolol & $0.05 \pm 0.01$ & $9.66 \pm 2.42 \times 10^{7}$ & 20.00 & $9.24 \pm 0.06$ & $8.75 \pm 0.05$ \\
\hline Cyanopindolol & $0.015 \pm 0.003$ & $2.99 \pm 0.23 \times 10^{8}$ & 66.67 & $10.34 \pm 0.09$ & $9.93 \pm 0.09$ \\
\hline CGP12177 & $0.08 \pm 0.02$ & $5.07 \pm 0.93 \times 10^{8}$ & 12.50 & $9.83 \pm 0.11$ & $9.50 \pm 0.22$ \\
\hline Isoprenaline & $4.77 \pm 1.74$ & $2.51 \pm 0.44 \times 10^{7}$ & 0.21 & $6.78 \pm 0.16$ & $6.49 \pm 0.09$ \\
\hline Salbutamol & $9.81 \pm 2.60$ & $1.96 \pm 0.77 \times 10^{7}$ & 0.10 & $4.91 \pm 0.02$ & $5.27 \pm 0.11$ \\
\hline CGP20712A & $0.22 \pm 0.03$ & $4.14 \pm 0.60 \times 10^{8}$ & 4.55 & $9.27 \pm 0.08$ & $8.75 \pm 0.06$ \\
\hline
\end{tabular}


bioRxiv preprint doi: https://doi.org/10.1101/2021.08.31.458064; this version posted September 1, 2021. The copyright holder for this preprint (which was not certified by peer review) is the author/funder, who has granted bioRxiv a license to display the preprint in perpetuity. It is made available under aCC-BY 4.0 International license.

Table 1 Kinetic binding parameters of unlabeled ligands for human $\beta_{1}$-adrenoceptor receptors. Data are mean \pm SEM for $\geq 3$ experiments performed in singlet. 


\section{Figures}

\section{Figure 1}
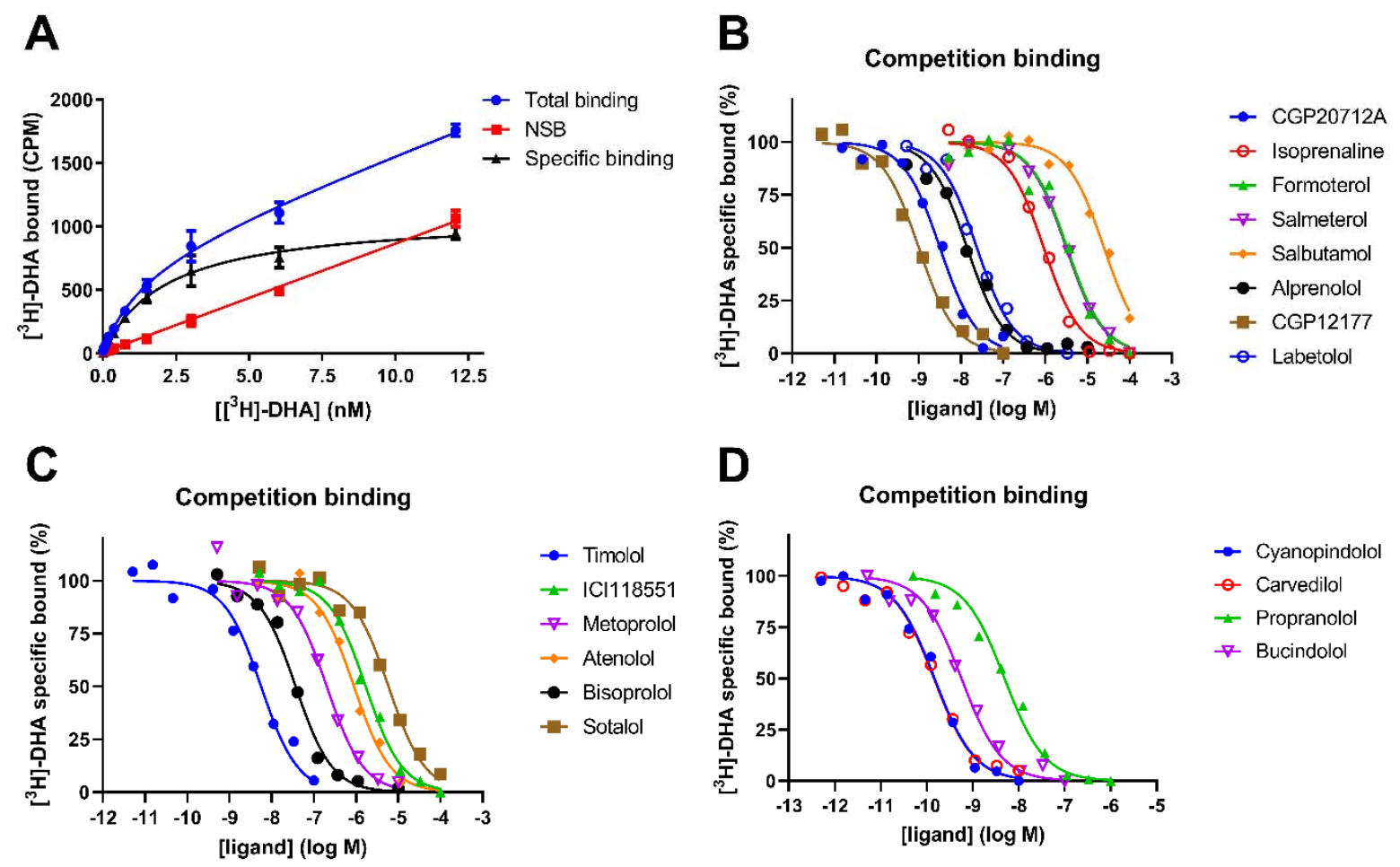

Figure 1. $\left[{ }^{3} \mathrm{H}\right]-\mathrm{DHA}$ saturation binding plus competition binding between $\left[{ }^{3} \mathrm{H}\right]-\mathrm{DHA}$ and $\beta$-adrenergic ligands for human $\beta_{1}$-adrenoceptors expressed in the $\mathrm{CHO}$ cells in the presence of GTP. (A) $\left[{ }^{3} \mathrm{H}\right]$-DHA saturation binding, Membranes (30 $\mu \mathrm{g}$ per well) from CHO- $\beta 1$ cells were incubated in HBSS containing $0.1 \mathrm{mM}$ GTP (as described in Methods) and increasing concentrations of radioligand for $180 \mathrm{~min}$ at $37^{\circ} \mathrm{C}$ with gentle agitation. Displacement of $\left[{ }^{3} \mathrm{H}\right]-\mathrm{DHA}(3 \mathrm{nM})$ by increasing concentrations of (B) CGP20712A, isoprenaline, formoterol, salmeterol, salbutamol, alprenolol, CGP12177 and labetolol. (C) timolol, ICl118,551, metoprolol, atenolol, bisoprolol, sotalol. (D) (S)cyanopindolol, carvedilol, propranolol and bucindolol. NSB was defined by $1 \mu \mathrm{M}$ propranolol. Data are presented as the mean \pm range from a representative of 3 experiments performed in singlet. 
Figure 2
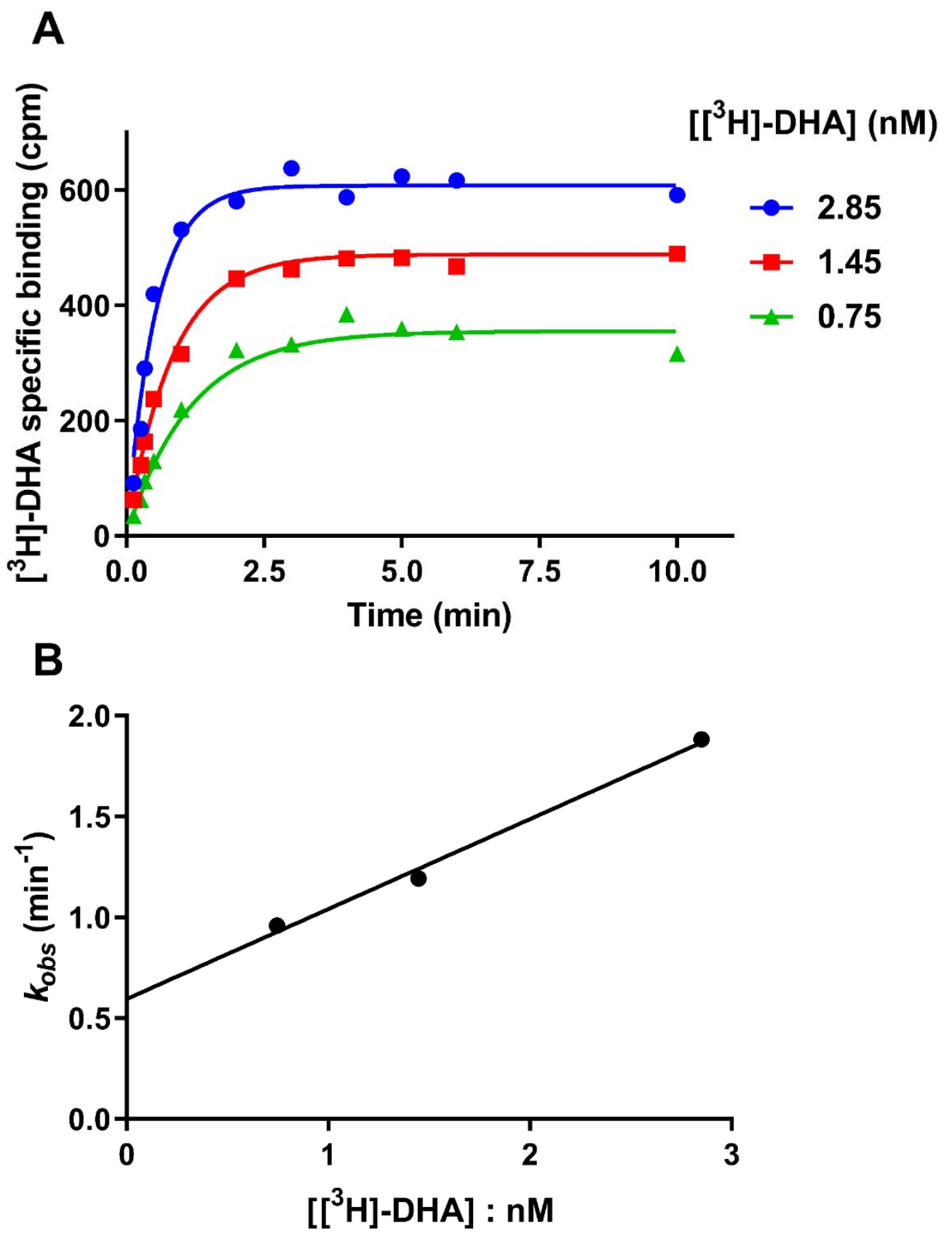

Figure 2. Determination of $\left[{ }^{3} \mathrm{H}\right]-\mathrm{DHA}$ kinetic binding parameters. (A) Observed association kinetics of the interaction of $\left[{ }^{3} \mathrm{H}\right]-\mathrm{DHA}$ with $\mathrm{CHO}$ membranes expressing the human $\beta_{1}$-adrenoceptors. (B) Plot of ligand concentration verses $k_{\mathrm{ob}}$. Binding followed a simple law of mass action model, $k_{\mathrm{ob}}$ increasing in a linear manner with radioligand 
bioRxiv preprint doi: https://doi.org/10.1101/2021.08.31.458064; this version posted September 1, 2021. The copyright holder for this preprint (which was not certified by peer review) is the author/funder, who has granted bioRxiv a license to display the preprint in perpetuity. It is made available under aCC-BY 4.0 International license.

concentration. Data are presented as the mean \pm range from a representative of 3 experiments performed in singlet. 


\section{Figure 3}

A

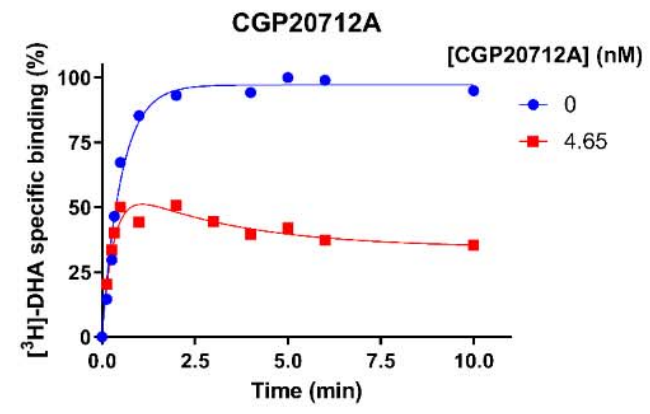

C

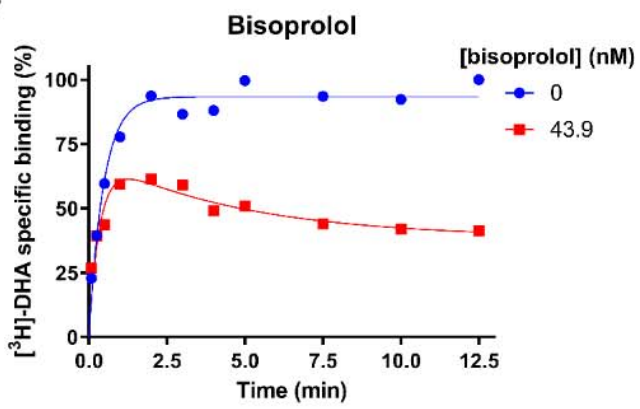

E

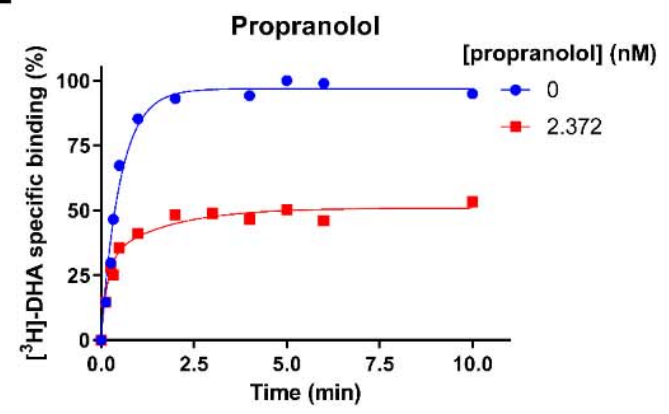

G

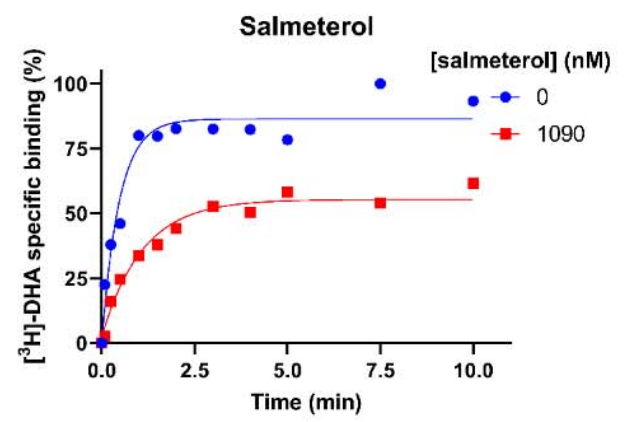

B

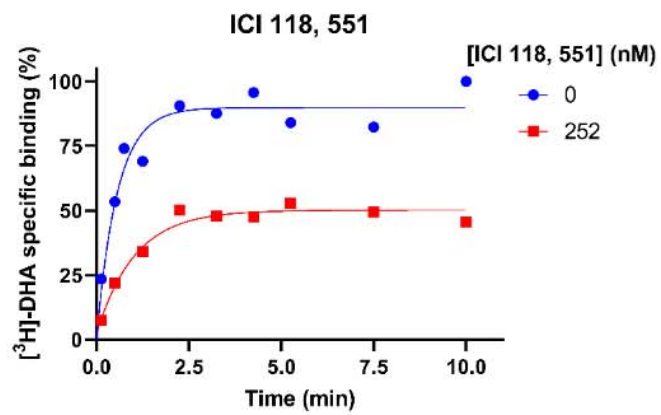

D

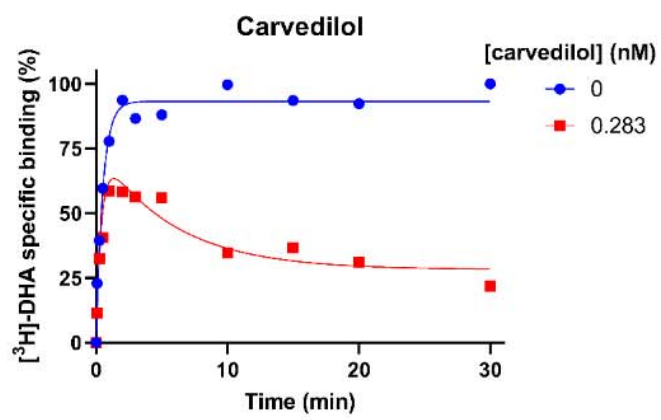

$\mathbf{F}$

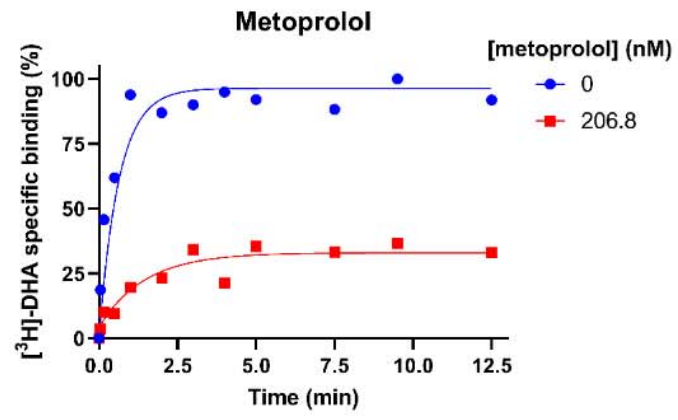

H

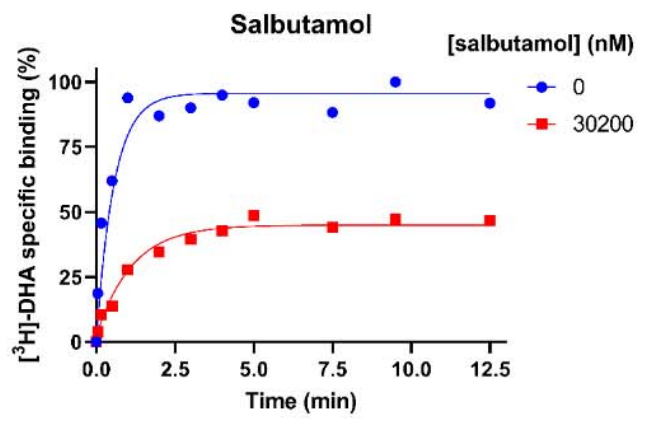

Figure 3. $\left[{ }^{3} \mathrm{H}\right]-\mathrm{DHA}$ competition kinetic curves in the presence of CGP20712A (A), ICl118,551(B), bisoprolol (C), carvedilol (D). propranolol (E) metoprolol (F) salmeterol 
and $\mathbf{( H )}$ salbutamol. $\mathrm{CHO}-\beta_{1}$ membranes were incubated with $\sim 3 \mathrm{nM}\left[{ }^{3} \mathrm{H}\right]-\mathrm{DHA}$ and either $0-, 1-, 3-, 10-$ or 100 -fold $K_{\mathrm{i}}$ of unlabeled competitor. Plates were incubated at $37^{\circ} \mathrm{C}$ for the indicated time points and NSB levels were determined in the presence of 1 $\mu \mathrm{M}$ propranolol. Data were fitted to the equations described in the Methods to calculate $k_{\text {on }}$ and $k_{\text {off }}$ values for the unlabelled ligands; these are summarized in Table 1. Data are presented as mean \pm range from a representative of $\geq 3$ experiments performed in singlet. 
Figure 4
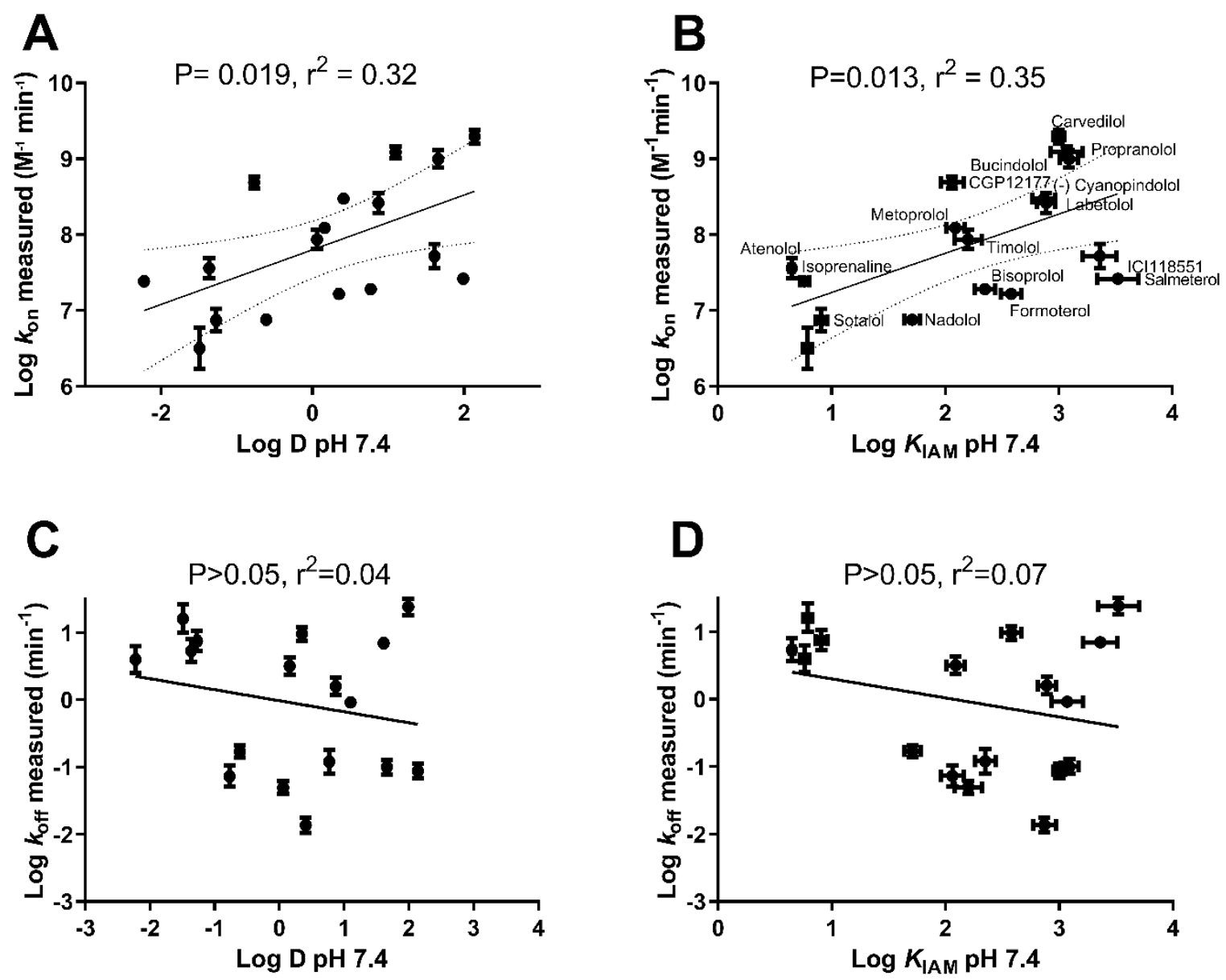

Figure 4. Correlating $\beta_{1}$ adrenoceptor ligand physiochemical parameters with kinetically derived parameters. Correlation plot showing the relationship between $(\mathbf{A}) \log k_{\mathrm{on}}$ and

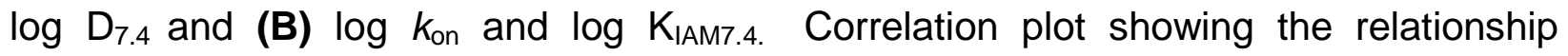
between (C) $\log k_{\text {off }}$ and $\log D_{7.4}$ and (D) $\log k_{\text {off }}$ and $\log K_{\text {IAM7.4. }}$ All data used in these plots are detailed in Table 1 with $\log D_{7.4}$ and log $K_{\text {IAM7.4 }}$ values from Sykes et al., 2014. Data are presented as mean \pm SEM from three or more experiments. 


\section{Figure 5}
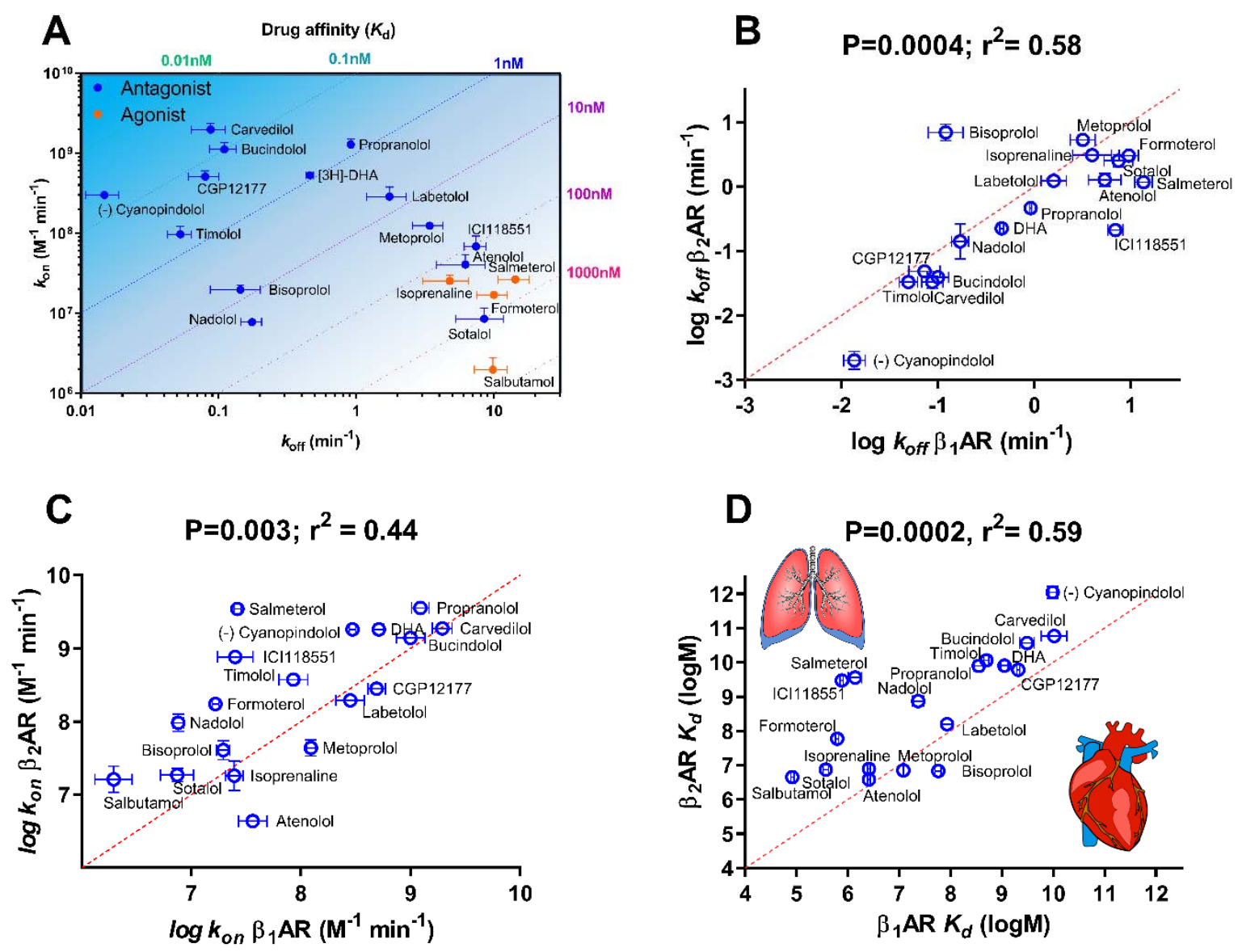

Figure 5. Summarizing the role of kinetics in dictating $\beta_{1}$-adrenoceptor affinity and selectivity. (A) Plot of $\beta_{1} A R k_{\text {off }}$ versus $\beta_{1} A R k_{\text {on }}$ values with affinity indicated by the diagonal dotted lines. (B) Plot of $\beta_{1} A R k_{\text {off }}$ versus $\beta_{2} A R k_{\text {off }}$ values. (C) Plot of $\beta_{1} A R k_{\text {on }}$ versus $\beta_{2} A R k_{\text {on }}$ values. (D) Plot of $\beta_{1} A R \log K_{d}$ versus $\beta_{2} A R \log K_{d}$ values. Kinetic values are presented as mean \pm SEM from three or more experiments detailed in Table 1. 
Figure 6
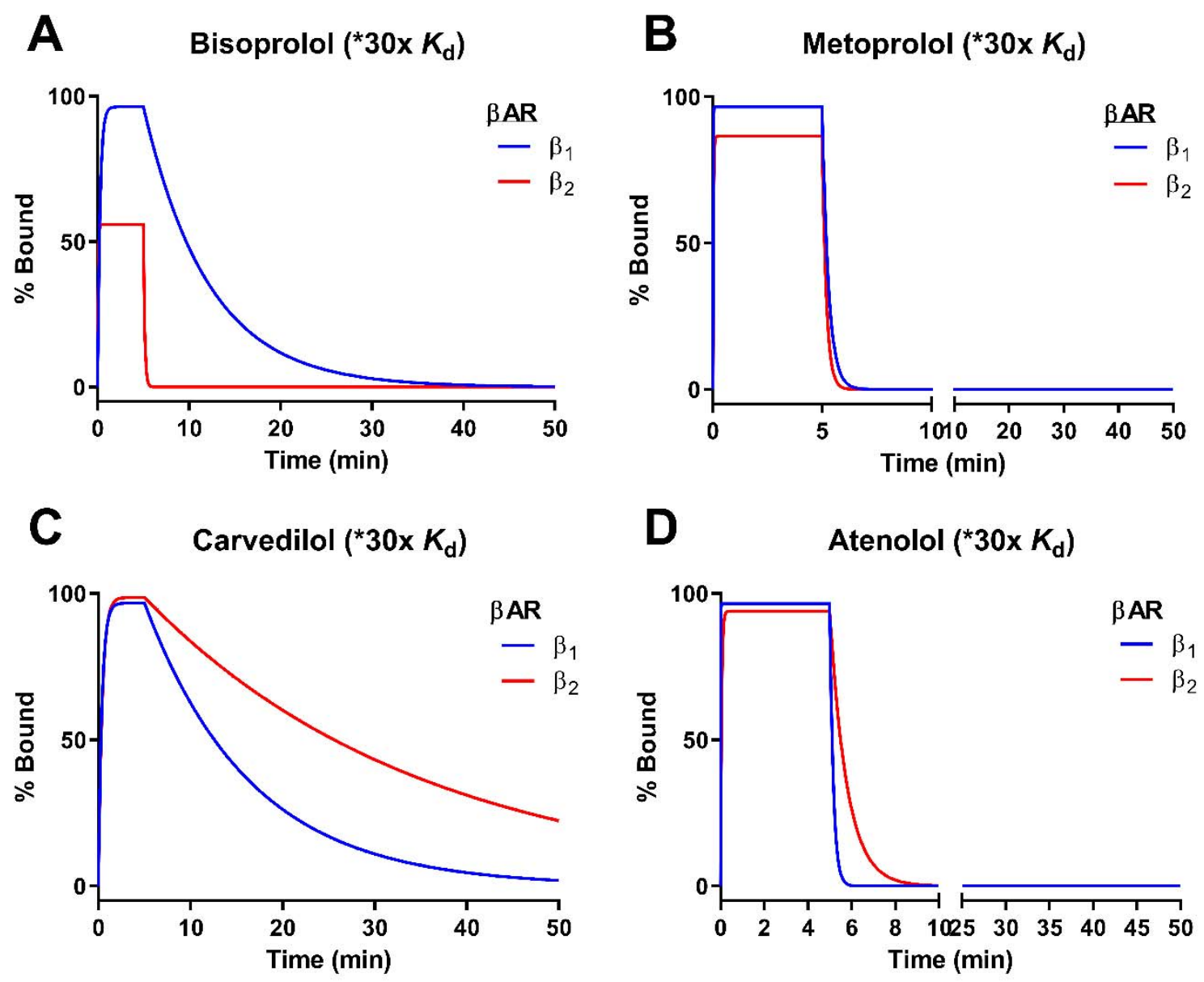

Figure 6. Summarizing the role of kinetics in dictating $\beta_{1}$-adrenoceptor selectivity. Modelling the association and dissociation of clinically relevant $\beta$-blockers. Simulated binding of clinically relevant $\beta$-blockers (A) bisoprolol (B) metoprolol (C) carvedilol and (D) atenolol to human $\beta_{1}$-adrenoceptors and $\beta_{2}$-adrenoceptors at concentrations $30^{*} K_{d}$ of the $\beta_{1}$-adrenoceptor.. Dissociation occurs at $5 \mathrm{~min}$ point initiated by the removal of free ligand. The kinetic parameters used to construct these simulations are detailed in Table 1 

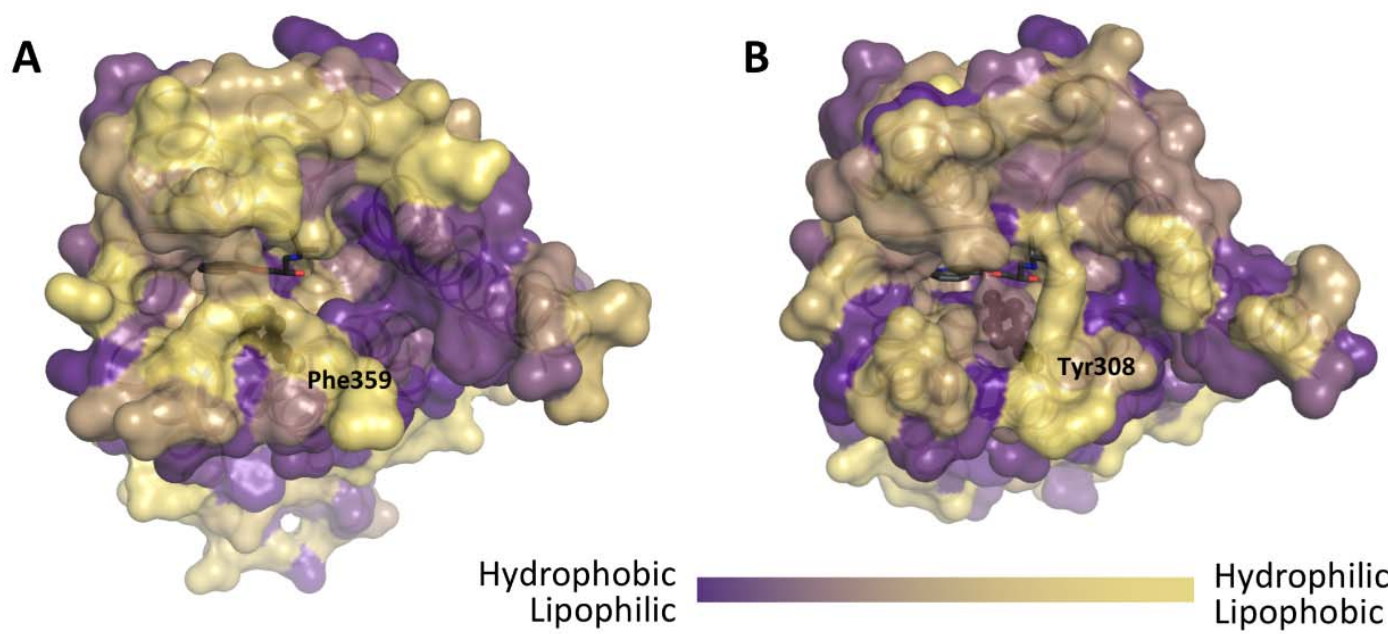

Lipophilic

Hydrophilic Lipophobic
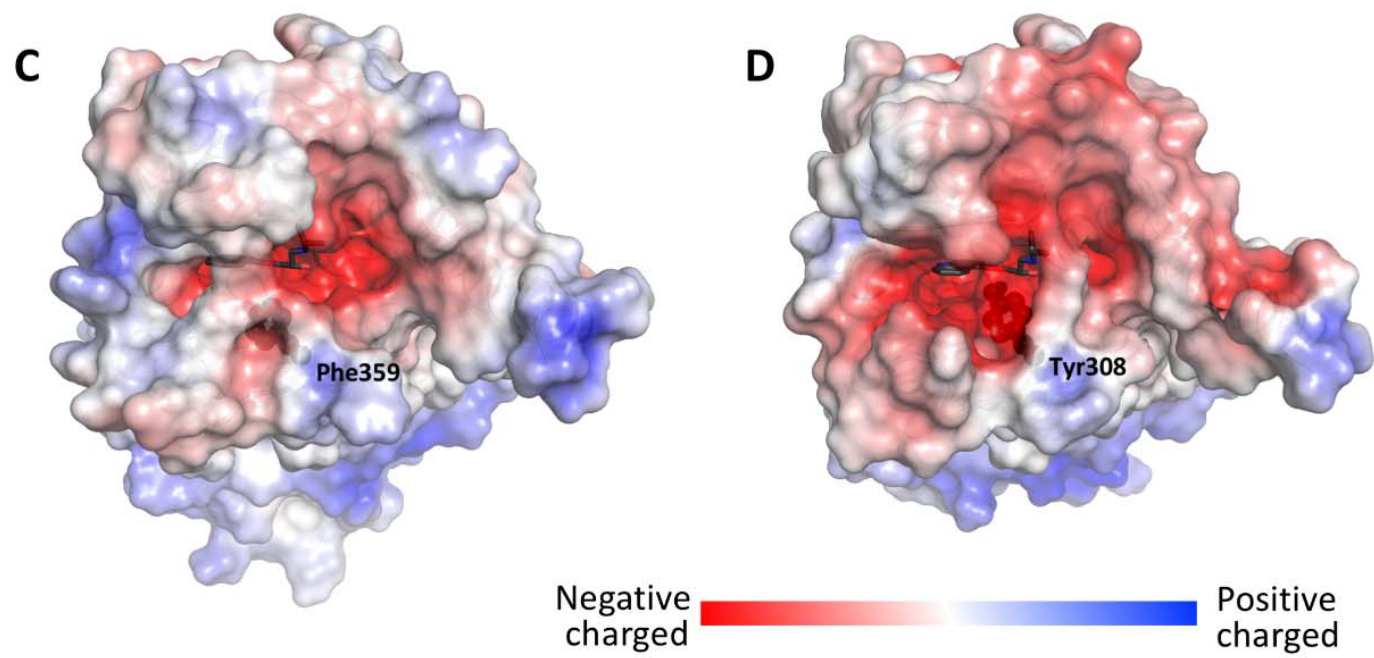

Negative
charged

Positive charged

Figure 7. Comparison of the extracellular surfaces including vestibules and orthosteric pockets between the human $\beta_{1} A R$ and $\beta_{2} A R$. Extracellular surface lipophilicity of the $\beta_{1} A R$ and $\beta_{2} A R$ is shown in $(A)$ and $(B)$ respectively. Extracellular surface polarity of the $\beta_{1} A R$ and $\beta_{2} A R$ is shown in (C) and (D) respectively. Overall, the surface of the $\beta_{2} A R$ is dominated by more negatively charged patches and its hydrophobic regions are more numerous and widely spread. 


\section{Supplemental File}

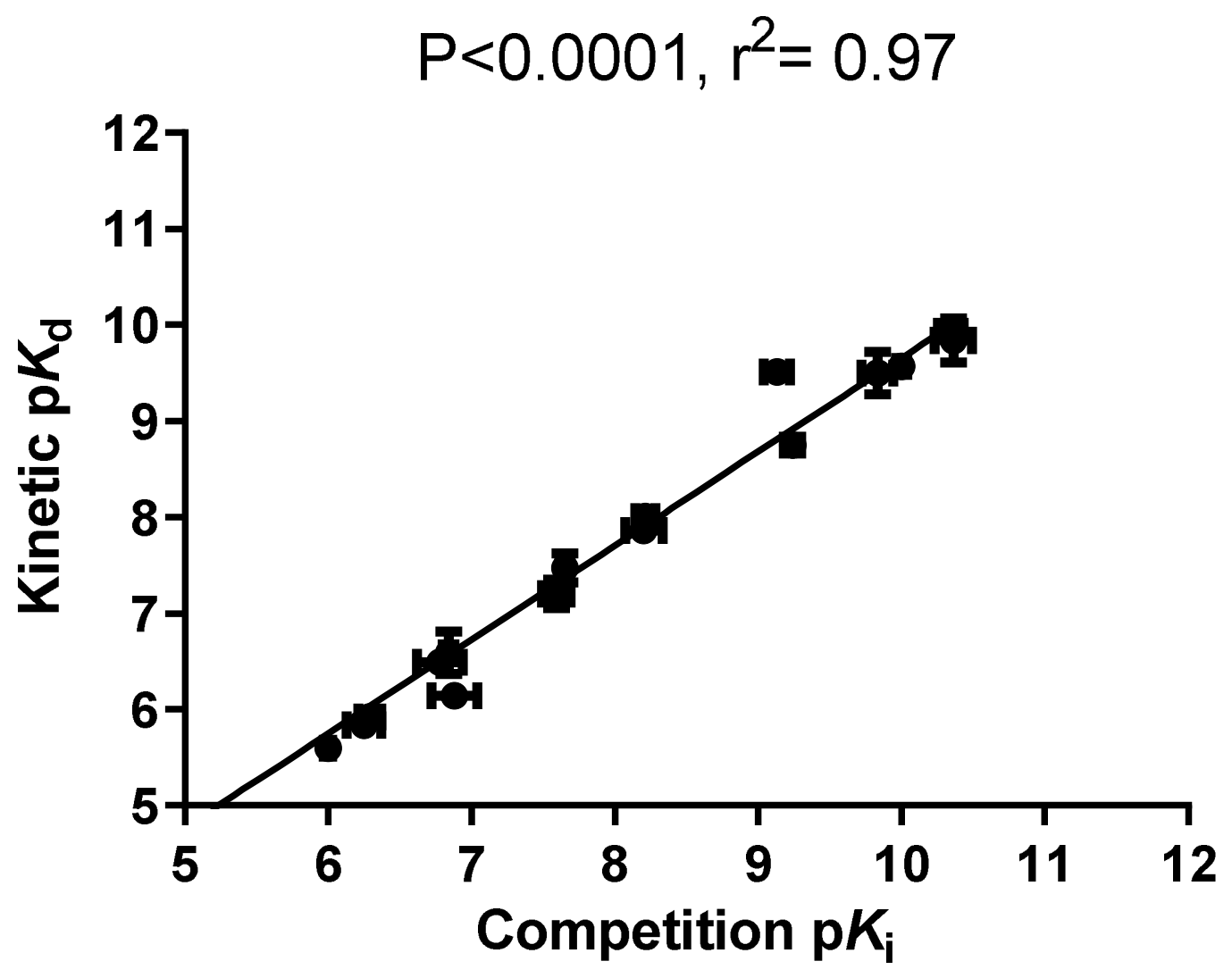

Supplemental Figure 1. Correlating kinetically derived parameters of $\beta_{1}$-adrenoceptor ligand. Correlation between $\mathrm{p} K_{\mathrm{i}}$ and kinetically derived $\mathrm{p} K_{\mathrm{i}}$ for the 17 test ligands. $\mathrm{p} K_{\mathrm{i}}$ values were taken from $\left[{ }^{3} \mathrm{H}\right]$-DHA competition binding experiments at equilibrium. The values composing the kinetically derived $K_{d}\left(k_{\text {off }} / k_{o n}\right)$ were taken from the experiments shown in Fig 4. All data used in these plots are detailed in Table 1. Data are presented as mean \pm S.E.M. from three or more experiments. 

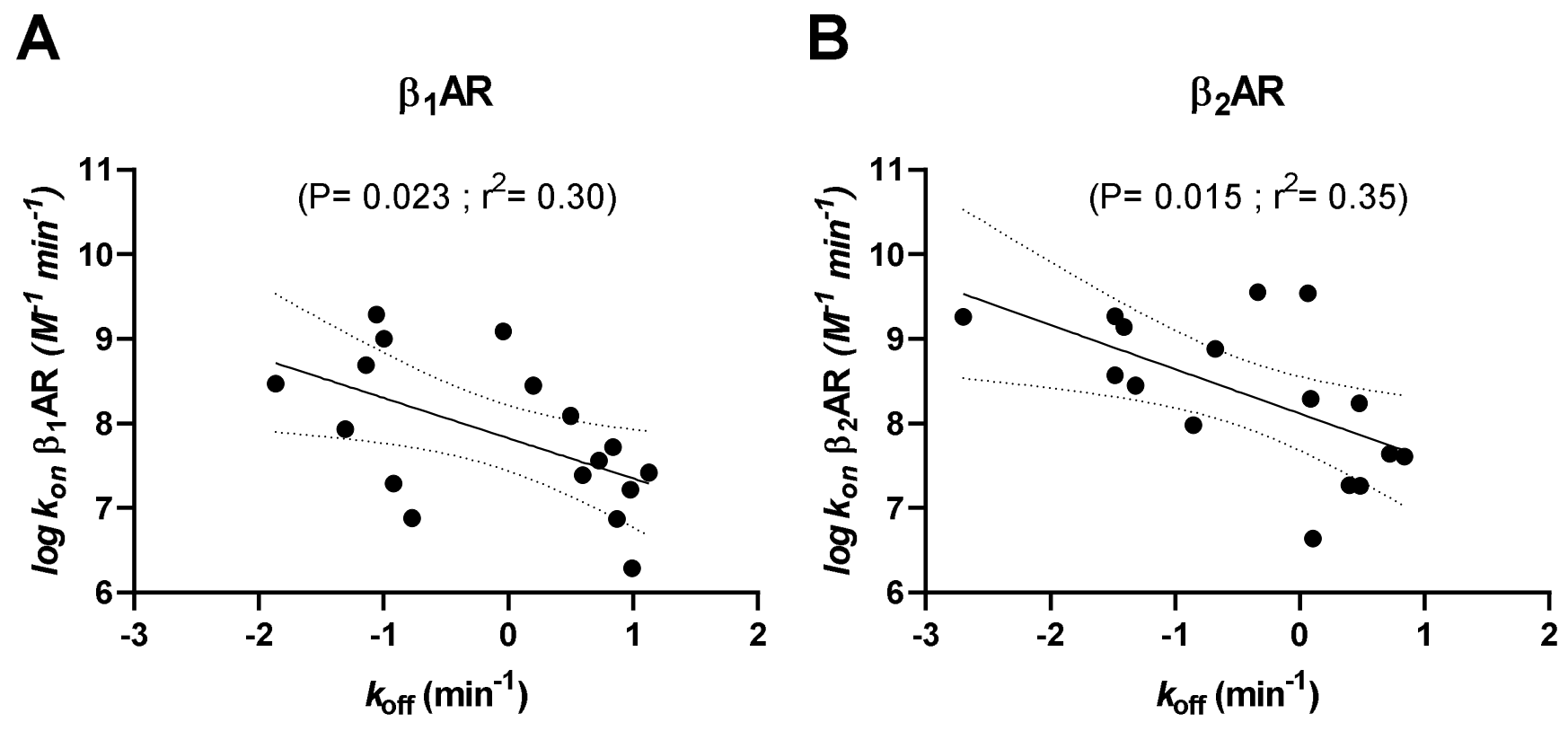

Supplemental Figure 2. Relationship between $k_{\text {off }}$ and $k_{\text {on }}$ values for ligands targeting $\beta$-adrenoceptor subtypes 1 and 2 . Kinetic values for ligands binding the $\beta_{2}$ adrenoceptor were taken from Sykes et al., 2014. 


\section{Supplemental references}

Sykes DA, Parry C, Reilly J, Wright P, Fairhurst RA, Charlton SJ (2014). Observed drug-receptor association rates are governed by membrane affinity: the importance of establishing "micro-pharmacokinetic/pharmacodynamic relationships" at the $\beta 2$ adrenoceptor. Mol Pharmacol. 85(4):608-17. 


\section{References}

Alexander, R.W., Williams, L.T., and Lefkowitz, R.J. (1975). Identification of cardiac beta-adrenergic receptors by (minus) [3H]alprenolol binding. Proc Natl Acad Sci U S A 72, 1564-1568.

AP, I.J., and Guo, D. (2019). Drug-Target Association Kinetics in Drug Discovery. Trends Biochem Sci 44, 861-871.

Avdeef, A., Box, K.J., Comer, J.E., Hibbert, C., and Tam, K.Y. (1998). pH-metric logP 10. Determination of liposomal membrane-water partition coefficients of ionizable drugs. Pharm Res 15, 209-215.

Baker, J.G. (2005). The selectivity of beta-adrenoceptor antagonists at the human beta1, beta2 and beta3 adrenoceptors. Br J Pharmacol 144, 317-322.

Baker, J.G. (2010). The selectivity of beta-adrenoceptor agonists at human beta1-, beta2- and beta3-adrenoceptors. Br J Pharmacol 160, 1048-1061.

Baker, J.G., Hill, S.J., and Summers, R.J. (2011). Evolution of beta-blockers: from antianginal drugs to ligand-directed signalling. Trends Pharmacol Sci 32, 227-234.

Baker, J.G., Proudman, R.G., and Hill, S.J. (2015). Salmeterol's extreme beta2 selectivity is due to residues in both extracellular loops and transmembrane domains. Mol Pharmacol 87, 103-120.

Baker, J.G., and Wilcox, R.G. (2017). beta-Blockers, heart disease and COPD: current controversies and uncertainties. Thorax 72, 271-276.

Benson, M.K., Berrill, W.T., Cruickshank, J.M., and Sterling, G.S. (1978). A comparison of four beta-adrenoceptor antagonists in patients with asthma. $\mathrm{Br} \mathrm{J}$ Clin Pharmacol 5, 415-419.

Bølling, R., Scheller, N.M., Køber, L., Poulsen, H.E., Gislason, G.H., and TorpPedersen, C. (2014). Comparison of the clinical outcome of different beta-blockers in 
heart failure patients: a retrospective nationwide cohort study. Eur J Heart Fail 16, 678684.

Boursier, M.E., Levin, S., Zimmerman, K., Machleidt, T., Hurst, R., Butler, B.L., Eggers, C.T., Kirkland, T.A., Wood, K.V., and Friedman Ohana, R. (2020). The luminescent HiBiT peptide enables selective quantitation of $\mathrm{G}$ protein-coupled receptor ligand engagement and internalization in living cells. J Biol Chem 295, 5124-5135.

Carter, C.M., Leighton-Davies, J.R., and Charlton, S.J. (2007). Miniaturized receptor binding assays: complications arising from ligand depletion. J Biomol Screen 12, 255266.

Choi, K.H., Lee, G.Y., Choi, J.O., Jeon, E.S., Lee, H.Y., Lee, S.E., Kim, J.J., Chae, S.C., Baek, S.H., Kang, S.M., et al. (2019). The mortality benefit of carvedilol versus bisoprolol in patients with heart failure with reduced ejection fraction. Korean J Intern Med 34, 1030-1039.

Costello, R.W., Jacoby, D.B., and Fryer, A.D. (1998). Pulmonary neuronal M2 muscarinic receptor function in asthma and animal models of hyperreactivity. Thorax 53, 613-616.

DiNicolantonio, J.J., Lavie, C.J., Fares, H., Menezes, A.R., and O'Keefe, J.H. (2013). Meta-analysis of carvedilol versus beta 1 selective beta-blockers (atenolol, bisoprolol, metoprolol, and nebivolol). Am J Cardiol 111, 765-769.

Dror, R.O., Pan, A.C., Arlow, D.H., Borhani, D.W., Maragakis, P., Shan, Y., Xu, H., and Shaw, D.E. (2011). Pathway and mechanism of drug binding to G-protein-coupled receptors. Proc Natl Acad Sci U S A 108, 13118-13123.

Dungen, H.D., Apostolovic, S., Inkrot, S., Tahirovic, E., Topper, A., Mehrhof, F., Prettin, C., Putnikovic, B., Neskovic, A.N., Krotin, M., et al. (2011). Titration to target dose of bisoprolol vs. carvedilol in elderly patients with heart failure: the CIBIS-ELD trial. Eur J Heart Fail 13, 670-680. 
Gherbi, K., Briddon, S.J., and Charlton, S.J. (2018). Micro-pharmacokinetics:

Quantifying local drug concentration at live cell membranes. Sci Rep 8, 3479.

Gillis, R.D., Botteri, E., Chang, A., Ziegler, A.I., Chung, N.C., Pon, C.K., Shackleford, D.M., Andreassen, B.K., Halls, M.L., Baker, J.G., et al. (2021). Carvedilol blocks neural regulation of breast cancer progression in vivo and is associated with reduced breast cancer mortality in patients. Eur J Cancer 147, 106-116.

Gonzalez, A., Perez-Acle, T., Pardo, L., and Deupi, X. (2011). Molecular basis of ligand dissociation in beta-adrenergic receptors. PLoS ONE 6, e23815.

Harries, A.D. (1981). Beta-blockade in asthma. Br Med J (Clin Res Ed) 282, 1321.

Harrington, J. (2020). Cardiac-specific beta-blockers and asthma: An end to fear? Respirology.

Hart, S.M. (2000). Influence of beta-blockers on mortality in chronic heart failure. Ann Pharmacother 34, 1440-1451.

Hulkower, S., Aiken, B.A., and Stigleman, S. (2015). Clinical inquiry: what is the best beta-blocker for systolic heart failure? J Fam Pract 64, 122-123.

Isberg, V., Mordalski, S., Munk, C., Rataj, K., Harpsoe, K., Hauser, A.S., Vroling, B., Bojarski, A.J., Vriend, G., and Gloriam, D.E. (2016). GPCRdb: an information system for G protein-coupled receptors. Nucleic Acids Res 44, D356-364.

Isogaya, M., Sugimoto, Y., Tanimura, R., Tanaka, R., Kikkawa, H., Nagao, T., and Kurose, H. (1999). Binding pockets of the beta(1)- and beta(2)-adrenergic receptors for subtype-selective agonists. Mol Pharmacol 56, 875-885.

Isogaya, M., Yamagiwa, Y., Fujita, S., Sugimoto, Y., Nagao, T., and Kurose, H. (1998). Identification of a key amino acid of the beta2-adrenergic receptor for high affinity binding of salmeterol. Mol Pharmacol 54, 616-622. 
Jabbal, S., Anderson, W., Short, P., Morrison, A., Manoharan, A., and Lipworth, B.J. (2017). Cardiopulmonary interactions with beta-blockers and inhaled therapy in COPD. QJM 110, 785-792.

Jabbour, A., Macdonald, P.S., Keogh, A.M., Kotlyar, E., Mellemkjaer, S., Coleman, C.F., Elsik, M., Krum, H., and Hayward, C.S. (2010). Differences between beta-blockers in patients with chronic heart failure and chronic obstructive pulmonary disease: a randomized crossover trial. J Am Coll Cardiol 55, 1780-1787.

Kang, J., More, K.N., Pyo, A., Jung, Y., Kim, D.Y., and Chang, D.J. (2021). Bisoprololbased (18)F-PET tracer: Synthesis and preliminary in vivo validation of beta1-blocker selectivity for beta1-adrenergic receptors in the heart. Bioorg Med Chem Lett 36, 127789.

Kaszuba, K., Rog, T., Bryl, K., Vattulainen, I., and Karttunen, M. (2010). Molecular dynamics simulations reveal fundamental role of water as factor determining affinity of binding of beta-blocker nebivolol to beta(2)-adrenergic receptor. J Phys Chem B 114, 8374-8386.

Kikkawa, H., Isogaya, M., Nagao, T., and Kurose, H. (1998). The role of the seventh transmembrane region in high affinity binding of a beta 2 -selective agonist TA-2005. Mol Pharmacol 53, 128-134.

Kim, I.M., Wang, Y., Park, K.M., Tang, Y., Teoh, J.P., Vinson, J., Traynham, C.J., Pironti, G., Mao, L., Su, H., et al. (2014). beta-arrestin1-biased beta1-adrenergic receptor signaling regulates microRNA processing. Circ Res 114, 833-844.

Kubota, Y., Asai, K., Furuse, E., Nakamura, S., Murai, K., Tsukada, Y.T., and Shimizu, W. (2015). Impact of beta-blocker selectivity on long-term outcomes in congestive heart failure patients with chronic obstructive pulmonary disease. Int J Chron Obstruct Pulmon Dis 10, 515-523. 
LaCroix, C., Freeling, J., Giles, A., Wess, J., and Li, Y.F. (2008). Deficiency of M2 muscarinic acetylcholine receptors increases susceptibility of ventricular function to chronic adrenergic stress. Am J Physiol Heart Circ Physiol 294, H810-820.

Lainscak, M., Podbregar, M., Kovacic, D., Rozman, J., and von Haehling, S. (2011). Differences between bisoprolol and carvedilol in patients with chronic heart failure and chronic obstructive pulmonary disease: a randomized trial. Respir Med 105 Suppl 1, S44-49.

Liao, K.M., Lin, T.Y., Huang, Y.B., Kuo, C.C., and Chen, C.Y. (2017). The evaluation of beta-adrenoceptor blocking agents in patients with COPD and congestive heart failure: a nationwide study. Int J Chron Obstruct Pulmon Dis 12, 2573-2581.

Liu, H., Carter, G.T., and Tischler, M. (2001). Immobilized artificial membrane chromatography with mass spectrometric detection: a rapid method for screening drugmembrane interactions. Rapid Commun Mass Spectrom 15, 1533-1538.

Mason, R.P., Rhodes, D.G., and Herbette, L.G. (1991). Reevaluating equilibrium and kinetic binding parameters for lipophilic drugs based on a structural model for drug interaction with biological membranes. J Med Chem 34, 869-877.

Masureel, M., Zou, Y., Picard, L.P., van der Westhuizen, E., Mahoney, J.P., Rodrigues, J., Mildorf, T.J., Dror, R.O., Shaw, D.E., Bouvier, M., et al. (2018). Structural insights into binding specificity, efficacy and bias of a beta2AR partial agonist. Nat Chem Biol $14,1059-1066$.

McCloskey, M.A., and Poo, M.M. (1986). Rates of membrane-associated reactions: reduction of dimensionality revisited. J Cell Biol 102, 88-96.

Metra, M., Cas, L.D., di Lenarda, A., and Poole-Wilson, P. (2004). Beta-blockers in heart failure: are pharmacological differences clinically important? Heart Fail Rev 9 , 123-130. 
Motulsky, H.J., and Mahan, L.C. (1984). The kinetics of competitive radioligand binding predicted by the law of mass action. Mol Pharmacol 25, 1-9.

Oberhauser, V., Schwertfeger, E., Rutz, T., Beyersdorf, F., and Rump, L.C. (2001). Acetylcholine release in human heart atrium: influence of muscarinic autoreceptors, diabetes, and age. Circulation 103, 1638-1643.

Peixoto, R., Pereira, M.L., and Oliveira, M. (2020). Beta-Blockers and Cancer: Where Are We? Pharmaceuticals (Basel) 13.

Plazinska, A., Kolinski, M., Wainer, I.W., and Jozwiak, K. (2013). Molecular interactions between fenoterol stereoisomers and derivatives and the beta(2)-adrenergic receptor binding site studied by docking and molecular dynamics simulations. J Mol Model 19, 4919-4930.

Plazinska, A., Plazinski, W., and Jozwiak, K. (2015). Agonist binding by the beta2adrenergic receptor: an effect of receptor conformation on ligand associationdissociation characteristics. Eur Biophys J 44, 149-163.

Rain, C., and Rada, G. (2015). Is carvedilol better than other beta-blockers for heart failure? Medwave 15 Suppl 1, e6168.

Ramos, I., Aparici, M., Letosa, M., Puig, C., Gavalda, A., Huerta, J.M., Espinosa, S., Vilella, D., and Miralpeix, M. (2018). Abediterol (LAS100977), an inhaled long-acting beta2-adrenoceptor agonist, has a fast association rate and long residence time at receptor. Eur J Pharmacol 819, 89-97.

Remme, W.J. (2010). Which beta-blocker is most effective in heart failure? Cardiovasc Drugs Ther 24, 351-358.

Ring, A.M., Manglik, A., Kruse, A.C., Enos, M.D., Weis, W.I., Garcia, K.C., and Kobilka, B.K. (2013). Adrenaline-activated structure of beta2-adrenoceptor stabilized by an engineered nanobody. Nature 502, 575-579. 
Sargent, D.F., and Schwyzer, R. (1986). Membrane lipid phase as catalyst for peptidereceptor interactions. Proc Natl Acad Sci U S A 83, 5774-5778.

Selvam, B., Wereszczynski, J., and Tikhonova, I.G. (2012). Comparison of dynamics of extracellular accesses to the beta(1) and beta(2) adrenoceptors binding sites uncovers the potential of kinetic basis of antagonist selectivity. Chem Biol Drug Des 80, 215-226.

Staus, D.P., Strachan, R.T., Manglik, A., Pani, B., Kahsai, A.W., Kim, T.H., Wingler, L.M., Ahn, S., Chatterjee, A., Masoudi, A., et al. (2016). Allosteric nanobodies reveal the dynamic range and diverse mechanisms of $\mathrm{G}$-protein-coupled receptor activation. Nature 535, 448-452.

Su, V.Y., Chang, Y.S., Hu, Y.W., Hung, M.H., Ou, S.M., Lee, F.Y., Chou, K.T., Yang, K.Y., Perng, D.W., Chen, T.J., et al. (2016). Carvedilol, Bisoprolol, and Metoprolol Use in Patients With Coexistent Heart Failure and Chronic Obstructive Pulmonary Disease. Medicine (Baltimore) 95, e2427.

Sykes, D.A., and Charlton, S.J. (2012). Slow receptor dissociation is not a key factor in the duration of action of inhaled long-acting beta2-adrenoceptor agonists. $\mathrm{Br} \mathrm{J}$ Pharmacol 165, 2672-2683.

Sykes, D.A., Dowling, M.R., Leighton-Davies, J., Kent, T.C., Fawcett, L., Renard, E., Trifilieff, A., and Charlton, S.J. (2012). The Influence of receptor kinetics on the onset and duration of action and the therapeutic index of NVA237 and tiotropium. J Pharmacol Exp Ther 343, 520-528.

Sykes, D.A., Parry, C., Reilly, J., Wright, P., Fairhurst, R.A., and Charlton, S.J. (2014). Observed drug-receptor association rates are governed by membrane affinity: the importance of establishing "micro-pharmacokinetic/pharmacodynamic relationships" at the beta2-adrenoceptor. Mol Pharmacol 85, 608-617.

Taniguchi, T., Ohtani, T., Mizote, I., Kanzaki, M., Ichibori, Y., Minamiguchi, H., Asano, Y., Sakata, Y., and Komuro, I. (2013). Switching from carvedilol to bisoprolol 
ameliorates adverse effects in heart failure patients with dizziness or hypotension. Journal of Cardiology 61, 417-422.

Tautermann, C.S., Kiechle, T., Seeliger, D., Diehl, S., Wex, E., Banholzer, R., Gantner, F., Pieper, M.P., and Casarosa, P. (2013). Molecular basis for the long duration of action and kinetic selectivity of tiotropium for the muscarinic M3 receptor. $\mathrm{J}$ Med Chem $56,8746-8756$.

Vanni, S., Neri, M., Tavernelli, I., and Rothlisberger, U. (2009). Observation of "ionic lock" formation in molecular dynamics simulations of wild-type beta 1 and beta 2 adrenergic receptors. Biochemistry 48, 4789-4797.

Vauquelin, G. (2016). Cell membranes... and how long drugs may exert beneficial pharmacological activity in vivo. Br J Clin Pharmacol 82, 673-682.

Vrakas, D., Giaginis, C., and Tsantili-Kakoulidou, A. (2008). Electrostatic interactions and ionization effect in immobilized artificial membrane retention. A comparative study with octanol-water partitioning. J Chromatogr A 1187, 67-78.

Warne, T., Edwards, P.C., Dore, A.S., Leslie, A.G.W., and Tate, C.G. (2019). Molecular basis for high-affinity agonist binding in GPCRs. Science 364, 775-778.

Warne, T., Moukhametzianov, R., Baker, J.G., Nehme, R., Edwards, P.C., Leslie, A.G., Schertler, G.F., and Tate, C.G. (2011). The structural basis for agonist and partial agonist action on a beta(1)-adrenergic receptor. Nature 469, 241-244.

Warne, T., Serrano-Vega, M.J., Baker, J.G., Moukhametzianov, R., Edwards, P.C., Henderson, R., Leslie, A.G., Tate, C.G., and Schertler, G.F. (2008). Structure of a beta1-adrenergic G-protein-coupled receptor. Nature 454, 486-491.

Weir, R.A., and Dargie, H.J. (2005). Carvedilol in chronic heart failure: past, present and future. Future Cardiol 1, 723-734. 
Wikstrand, J., Wedel, H., Castagno, D., and McMurray, J.J. (2014). The large-scale placebo-controlled beta-blocker studies in systolic heart failure revisited: results from CIBIS-II, COPERNICUS and SENIORS-SHF compared with stratified subsets from MERIT-HF. J Intern Med 275, 134-143.

Wisler, J.W., DeWire, S.M., Whalen, E.J., Violin, J.D., Drake, M.T., Ahn, S., Shenoy, S.K., and Lefkowitz, R.J. (2007). A unique mechanism of beta-blocker action: carvedilol stimulates beta-arrestin signaling. Proc Natl Acad Sci U S A 104, 16657-16662.

Xu, X., Kaindl, J., Clark, M.J., Hubner, H., Hirata, K., Sunahara, R.K., Gmeiner, P., Kobilka, B.K., and Liu, X. (2020). Binding pathway determines norepinephrine selectivity for the human beta1AR over beta2AR. Cell Res. 